\title{
Unsteady Extinction Of Opposed Jet Ethylene / Methane HIFiRE Surrogate Fuel Mixtures vs Air
}

\author{
Sarah N. Vaden ${ }^{\prime}$, Rachel L. Debes ${ }^{2}$, E. Lara Lash ${ }^{3}$, Rachel S. Burk ${ }^{4}$, C. Merritt Boyd ${ }^{5}$, \\ ${ }^{I}$ Georgia Tech, Atlanta, GA; ${ }^{2}$ U of Kansas, Lawrence, KA; ${ }^{3}$ G.C. Marshall HS, Falls Church, VA; ${ }^{4}$ U.S. Air Force \\ Academy, Colorado Springs, CO; ${ }^{5}$ North Cross HS, Roanoke, VA; \\ Lloyd G. Wilson ${ }^{6}$ and Gerald L. Pellett ${ }^{7}$ \\ ${ }^{6}$ Lockheed Martin Space Ops, Hampton, VA; ${ }^{7}$ NASA Langley Research Center, MS 168, Hampton, VA 23681
}

A unique idealized study of the subject fuel vs. air systems was conducted using an Oscillatory-input Opposed Jet Burner (OOJB) system and a newly refined analysis. Extensive dynamic-extinction measurements were obtained on unanchored (free-floating) laminar Counter Flow Diffusion Flames (CFDFs) at 1-atm, stabilized by steady input velocities (e.g., $U_{\text {air }}$ ) and perturbed by superimposed in-phase sinusoidal velocity inputs at fuel and air nozzle exits. Ethylene $\left(\mathrm{C}_{2} \mathrm{H}_{4}\right)$ and methane $\left(\mathrm{CH}_{4}\right)$, and intermediate 64/36 and 15/85 molar percent mixtures were studied. The latter gaseous surrogates were chosen earlier to mimic ignition and respective steady Flame Strengths (FS $=U_{\text {air }}$ ) of vaporized and cracked, and un-cracked, JP-7 "like" kerosene for a Hypersonic International Flight Research Experimentation (HIFiRE) scramjet. For steady idealized flameholding, the $100 \% \mathrm{C}_{2} \mathrm{H}_{4}$ flame is respectively $\sim 1.3$ and $\sim 2.7$ times stronger than a 64/36 mix and $\mathrm{CH}_{4}$; but is still 12.0 times weaker than a $100 \% \mathrm{H}_{2}$-air flame. Limited Hot-Wire (HW) measurements of velocity oscillations at convergent-nozzle exits, and more extensive Probe Microphone (PM) measurements of acoustic pressures, were used to normalize Dynamic FSs, which decayed linearly with $\mathrm{pk} / \mathrm{pk} U_{\text {air }}$ (velocity magnitude, HW), and also pk/pk $P$ (pressure magnitude, PM). Thus Dynamic Flame Weakening (DFW) is defined as $\%$ decrease in FS per Pascal of pk/pk $P$ oscillation, namely, DFW $=-100 \mathrm{~d}\left(U_{\mathrm{air}} / U_{\mathrm{air}, 0 \mathrm{~Hz}}\right) / \mathrm{d}(\mathrm{pkpk}$ $P)$. Key findings are: (1) Ethylene flames are uniquely strong and resilient to extinction by oscillating inflows below $150 \mathrm{~Hz}$; (2) Methane flames are uniquely weak; (3) Ethylene / methane surrogate flames are disproportionately strong with respect to ethylene content; and (4) Flame weakening is consistent with limited published results on forced unsteady CFDFs. Thus from 0 to $\sim 10 \mathrm{~Hz}$ and slightly higher, lagging diffusive responses of key species led to progressive phase lags (relative to inputs) in the oscillating flames, and caused maximum weakening. At 20 to 150 Hz, diffusion-rate-limited effects diminished, causing flames to "regain strength," and eventually become completely insensitive beyond $300 \mathrm{~Hz}$. Detailed mechanistic understanding is needed. Overall, ethylene flames are remarkably resilient to dynamic extinction by oscillating inflows. They are the strongest, with the notable exception of $\mathrm{H}_{2}$. For HIFiRE tests, the $64 \% / 36 \%$ surrogate disproportionally retains the high dynamic FS of ethylene, so the potential for loss of scramjet flameholding (flameout) due to low frequency oscillations is significantly mitigated.

\footnotetext{
${ }^{1}$ Georgia Tech; Atlanta, GA. svaden3@mail.gatech.edu

${ }^{2}$ U. of Kansas; Lawrence, KS. rldebes@gmail.com

${ }^{3}$ NASA-VA Governor's School; now Lafayette College; Easton, PA. priderock1991@aim.com

${ }^{4}$ The U.S Air Force Academy; Colorado Springs, CO. C12Rachel.Burke@usafa.edu (also) schwestigs08@verizon.net

${ }^{5}$ NASA-VA Governor's School; now Virginia Tech; Blacksburg, VA. Chaos08@gmail.com

${ }^{6}$ Lockheed Martin Space Operations; Hampton, VA. 1.g.wilson@larc.nasa.gov

${ }^{7}$ Senior Research Scientist, Hypersonic Air Breathing Propulsion Branch/RTG; Senior Member, AIAA. g.l.pellett@larc.nasa.gov
}

Approved for public release; distribution is unlimited. 


\section{Nomenclature}

$\begin{array}{ll}D_{\mathrm{t}} & =\text { Tube diameter } \\ D_{\mathrm{n}} & =\text { Nozzle Diameter } \\ p k / p k P & =\text { peak-to-peak Pressure oscillation magnitude } \\ p k / p k V & =\text { peak-to-peak Velocity oscillation magnitude } \\ p k / p k v & =\text { peak-to-peak voltage on speaker } \\ T & =\text { temperature } \\ U_{\text {air }} & =\text { Air velocity, cross section average } \\ U_{\text {fuel }} & =\text { Fuel velocity, cross section average } \\ \text { CFDF } & =\text { Counter Flow Diffusion Flame } \\ \text { FS } & =\text { Flame Strength }\left(=U_{\text {air }} \text { at near-steady-state extinction) }\right. \\ \text { ASR } & =\text { Applied Stress Rate }\left(=U_{\text {air }} / D_{\text {tor }}\right) \\ \text { Dynamic FS } & =\text { Dynamic Flame Strength }\left(=U_{\text {air }} \text { at extinction, for defined oscillation magnitude and frequency) }\right. \\ \text { DFW } & =\text { Dynamic Flame Weakening, }\left(\% \text { decrease in } U_{\text {air }}\right) / \mathrm{Pa}, \text { compared to steady } U_{\text {air }} \text { at extinction } \\ \text { HW } & =\text { Hot Wire } \\ \text { PM } & =\text { Probe Microphone } \\ \text { SLPM } & =\text { Standard liters per minute mass flow rate at } 273 \mathrm{~K}\end{array}$

\section{Introduction}

$\mathrm{T}$ URBULENT non-premixed hydrocarbon-air flames are frequently exposed to strong acoustic fields in practical combustion devices, but research in characterizing the fundamentals of perturbed flameholding has been sporadic. ${ }^{1-5}$ Although our applied objective is to better understand key physical/chemical flameholding processes in an idealized gaseous hydrocarbon-fueled airbreathing scramjet configuration for the Hypersonic International Flight Research Experimentation (HIFiRE) project, such engines represent but one of many different applications that may be affected. Despite a brief surge of interest in unsteady flames during the early 1990 's, ${ }^{3-15}$ much remains to be understood regarding specific physical/chemical effects of flow oscillations on the structure and extinction of even the simplest dynamically strained diffusion flames. Most of the current knowledge stems from large-activationenergy asymptotic analyses ${ }^{6,8,9}$ and numerical simulations., ${ }^{5,711,12}$ The few known experimental studies have emphasized detailed non-intrusive measurements of species, temperature, and velocity, and resultant axial strain rates in methane-air and propane-air systems at relatively low strain rates and frequencies. ${ }^{10,13-15}$ Note that possible thermo-acoustic instabilities that may be encountered in various premixed combustion devices are not included in this study.

Four fuel compositions were examined here in relation to the fundamental properties of simple gaseous surrogate fuels for Flight 2 of the HIFiRE project. Participants include: NASA Langley; U.S. Air Force AFRL; ATK Alliant Tech Systems; and the Australian Defence Science and Technology Organization, DSTO. In the recent past, our primary focus has been on the exceptional properties of steady flames based on ethylene mixed with methane or ethane. In this study, dynamic data for $64 / 36$ and $15 / 85$ (mole \% ethylene)/(mole \% methane) mixtures were obtained and analyzed in combination with previous results for the pure component flames. The respective fuel mixtures were recommended as simple gaseous surrogates in the author's "near-steady-state" extinction studies in 2007 and $2008^{16,18}$ on the basis they have steady Flame Strengths equivalent to those for vaporized, cracked and uncracked, JP-7 "like" kerosene fuel.

\section{A. Background on Steady Extinction of Hydrocarbon vs. Air CFDFs}

Recently we described methodology used to define surrogate hydrocarbon (HC) fuel mixtures for the subject HIFiRE project. ${ }^{16}$ The process of selectively defining and characterizing a simple gaseous HC surrogate fuel capable of igniting and combusting in a supersonic HIFiRE test flight - and mimic the flameholding (flameout) performance of a vaporized and cracked JP-7 "like" fuel in a scramjet combustor - was discussed in detail. In short, it was recommended that Opposed Jet Burner (OJB) extinction limits of non-premixed flames of binary gaseous fuel mixtures at 1-atm should be considered a good basis for initial assessment of strain-rate-limited combustion rates in the subsonic recirculation region of a representative scramjet cavity flameholder.

Thus OJB extinction-limit data were obtained from laminar non-premixed HC vs. air Counter Flow Diffusion Flames (CFDFs) at 1-atm. Flame Strength (FS) was defined as a strain-induced extinction limit based on the crosssection-average air jet velocity, $U_{\text {air, }}$ which sustains combustion of a counter jet of gaseous fuel just before extinction. It was argued that FS uniquely characterizes a near-kinetically limited fuel combustion rate under 
conditions where fuel diffusion rate from the stagnation point is fast enough so it is not rate limiting; note, however, molecular diffusion is still important within the flames. ${ }^{17}$ And more generally, Applied Stress Rates (ASRs) were defined at extinction by normalizing $U_{\text {air }}$ data using nozzle or tube diameter, $D_{\mathrm{n} \text { or t }}{ }^{16,18,29}$

As a result, extinction measurements on $\mathrm{HC}$-air flames were characterized under idealized experimental conditions for four binary gaseous HC systems, including two ternary gaseous systems and a ternary system with vaporized $n$-heptane. ${ }^{16,18}$ First, FS and ASR results for pure HCs and mixtures allowed comparisons with detailed 1$\mathrm{D}$ and 2-D numerical simulations, as tests of available chemical kinetic models at 1-atm (discussed later). Second, the combined FS results helped characterize and define three candidate surrogate $\mathrm{HC}$ fuel mixtures. These surrogates exhibited a common FS $\left(\mathrm{ASR}_{\mathrm{t}}=160 \mathrm{1} / \mathrm{s}\right)$ that also matched our measured FS for Colket and Spadaccini's suggested ternary surrogate (60 mole \% ethylene, $30 \%$ methane, and $10 \% n$-heptane, based on ignition data ${ }^{19}$ ); in addition, the same FS was 70\% greater than measured for pure JP-7 fuel $(931 / \mathrm{s})$. Our primary candidate surrogate was a binary mixture of $64 \%$ ethylene $+36 \%$ methane. Uncracked JP-7 had the same FS as a $15 \%$ ethylene $+85 \%$ methane mixture. Thus a simple gaseous surrogate fuel was defined to mimic the critical flameholding (flameout) limit of a thermally- or catalytically-cracked JP-7 "like" fuel in HIFiRE scramjet combustion tests. ${ }^{16,18}$

The above papers ${ }^{16,18}$ further characterized pure and $\mathrm{N}_{2}$-diluted fuel systems to account for the various detailed effects on FS of temperature, pressure, jet diameter, inflow Reynolds number, inflow velocity profile (plug from contoured nozzle; parabolic from straight tube) and fuel composition. The resultant ASRs at extinction were also used to construct an "idealized dual-reactivity flameholding scale" "16,18 that showed wide ranging (50 times) ASRs at extinction for respective plug and parabolic inflows. Various pure vaporized-liquid and gaseous HCs were colocated on this scale. These included, in ascending order: JP-10, methane, JP-7, $n$-butane, $n$-heptane, propane, propylene, $n$-dodecane, ethane, the $64 \%$ ethylene / $36 \%$ methane surrogate, and ethylene. Additional results from earlier $\mathrm{H}_{2}$-air studies marked a unique and exceptionally strong flame (35 times stronger than methane) that agreed within $\sim 1 \%$ of a recent 2 -D numerically simulated FS for a $3 \mathrm{~mm}$ tube-OJB. ${ }^{20}$ It was concluded that "through comparisons with earlier OJB characterizations, normalized (ASR) results exemplify a sensitive accurate means of validating, globally, complete and reduced chemical kinetic models at the relatively low temperatures that govern the loss of non-premixed "idealized" flameholding at near-atmospheric pressure, e.g., in scramjet combustors."

More recently, respective measured ASRs at extinction were effectively translated to absolute (local) axial strain rate scales on the airside of CFDFs, ${ }^{16}$ based on extensive Particle Imaging Velocimetry (PIV) and Laser Doppler Velocimetry (LDV) velocity surveys, ${ }^{21,22}$ numerical simulations, ${ }^{20,23,24}$ and independently published strain rate surveys using convergent nozzles. ${ }^{25}$ As a result, derived absolute strain rates can be compared directly with extinction limits determined numerically using either a 1-D, or preferably 2-D, Navier Stokes simulations with detailed transport rates and finite rate kinetics. Initially, numerical extinction results for methane, ${ }^{23}$ based on relatively well-validated chemical kinetics, agreed quite closely (within $<10 \%$ ) with the absolute strain rate scale. ${ }^{16}$ However, numerically simulated extinction results for ethylene averaged about $45 \%$ high for three different chemical kinetic models. ${ }^{16}$ Since the writer's "kinetics challenge," very recent numerical simulations and independent experimental results are now in excellent agreement with our 2008 ethylene-air extinction results (within $5 \%$ ), as detailed below.

Chelliah's very recent 1-D numerical simulation result for extinction of ethylene-air CFDFs at 1-atm was 1108 $1 / \mathrm{s}$ when expressed as an absolute (local) axial strain rate near the airside edge of a flame. ${ }^{24}$ The simulation used the USC 2009 kinetic model (modified 2007 model) and a revised set of binary diffusion coefficients. ${ }^{24}$ The $11081 / \mathrm{s}$ compares with our measured extinction limit on an absolute basis ${ }^{16}$ of $10881 / \mathrm{s}$ (from a $7.2 \mathrm{~mm}$ convergent nozzleOJB), and $1034 \mathrm{1} / \mathrm{s}$ (from a $7.56 \mathrm{~mm}$ straight-tube-OJB). And finally, both of the above can be compared to Chelliah's newly reported experimental measurement(s) averaging 1050 1/s, and based on PIV measurements of the airside input velocity field from opposed matched $7.95 \mathrm{~mm}$ convergent nozzles. ${ }^{24}$ Thus, since the above 1-D numerical simulations of extinction match our experimental results within $\sim 5 \%$, and bound a nearly 3 -fold range of FS (for methane to ethylene), intermediate experimental ASRs for five gaseous fuels (neat and blended) that closely fit the same dual flameholding scale should also offer accurate global tests of chemical kinetic models at 1-atm and the initial gas temperatures of $300 \mathrm{~K}$ (usually), and sometimes up to $600 \mathrm{~K}$.

\section{B. Dynamic Extinction of Hydrocarbon vs. Air CFDFs}

We now address the unsteady state flame extinction behavior of the same non-premixed gaseous-hydrocarbon vs air flames considered most relevant to HIFiRE. By using Oscillatory fuel- and air-inputs with a convergent-nozzle Opposed Jet Burner (OOJB) system that was applied to earlier steady-state studies, ${ }^{21,22,26-33}$ we conducted an idealized study of the dynamic weakening of fuel-air systems at frequencies from 8 to $1600 \mathrm{1} / \mathrm{s}$. Compared with our previously published dynamic study, ${ }^{32,33}$ the present work features substantially improved analyses of the dynamic extinction of ethylene-air and methane-air flames. Additionally, the present work contains the newly defined 64/36 
and 15/85 (mole \% ethylene / mole \% methane) fuel-air systems that represent cracked and un-cracked JP-7 "like" fuels. Finally, a new interpretation of the system response at low frequencies now leads to a simpler and more fundamental set of conclusions, compared to Refs. 32 and 33.

Thus several hundred dynamic-extinction "Flame Strength" measurements were obtained on unanchored (freefloating) laminar CFDFs, formed and centered by steady input flows, and perturbed by superimposed sinusoidal velocity inputs (all in-phase). We define unsteady-state Flame Strength as the maximum average air input velocity ( $U_{\text {air, }}$ at nozzle exit) a CFDF, with oscillatory axial velocity inputs of prescribed frequency and amplitude, can sustain before it extinguishes suddenly. As with steady FS, extinction is due to increasing net heat loss and a precipitous decline in temperature. ${ }^{29}$

Although steady FSs can be defined quite accurately by measurements of the maximum axial velocity gradient (strain rate) near the airside edge of a steady flame close to extinction, ${ }^{29}$ truly nonintrusive measurements are difficult and probably still inadequate for dynamic FSs over wide ranging frequencies. A simple explanation is that the input velocity gradient (strain rate) under dynamic conditions will vary transiently (and complexly) with axial position and magnitude and frequency of applied input velocity oscillations (pk/pk $U_{\mathrm{air}}$ ). Furthermore, any successful gauging of Dynamic FS by a sinusoidal-maximum axial strain rate near the airside edge may still imperfectly reflect maximum radial strain rate in the all-important flame core. Thus due to the probable complexity, definitive measurements and deductions of transient properties and transport effects were not considered feasible. Instead, global extinction parameters and Probe Microphone pk/pk $P$ cold-flow measurements were ultimately used to assess Dynamic FS over a wide range of frequencies - after early limited attempts to characterize key features of the flow field at low frequencies, as described below.

Our earliest measurements of dynamic extinction were supported by limited Hot Wire measurements of cold flows at frequencies up to $120 \mathrm{~Hz}$; later we used more extensive Probe Microphone cold-input-flow calibrations at frequencies from 4 to $1600 \mathrm{~Hz}$. Surprisingly, the latter enabled high quality characterizations of the dynamic weakening of each hydrocarbon-air system in the presence of very large system resonances at various frequencies (shown later).

Thus, the present data analyses and comparisons with published analytic and numerical results offer new insight on: (1) The transition from quasi-steady to dynamic flame extinction at very low frequencies; (2) the apparent effects of dynamic strain on diffusive-transport with increasing frequency, in which diffusion flames weaken to a maximum extent as they depart significantly from steady state; (3) the "re-strengthening" of flames at higher frequencies, where progressive diffusive responses become much smaller and their effects on FS are reduced; and, (4) the development of complete insensitivity to high-frequency perturbations.

Finally, with particular application to airbreathing scramjet engines, we recognize that critical localized subsonic "incipient" flameholding processes are typically associated with fuel injections that "feed" reacting recirculation zones having "sufficient" residence-time distributions. ${ }^{34,35}$ Such incipient flames may be weakened and extinguished by dynamically perturbed, frequency-sensitive diffusion processes involving $\mathrm{H}$-atom, $\mathrm{OH}$ and key $\mathrm{HC}$ species in a reaction zone with "laminar-flamelet-like" combustion. ${ }^{8-15,34,35}$ Because such limitations may cause the loss of "robust" flameholding, and possibly generalized flameout, it is important to characterize these dynamic effects at relatively low frequencies (say, $<150 \mathrm{~Hz}$ ), and begin to assess the potential for their occurrence in scramjets. Thus, further detailed measurements of low frequency acoustic fields appear needed to assess possible effects on critical flameholding in ground-based and flight tests of scramjet engine configurations.

\section{Experimental Approach}

\section{A. System Descriptions and Characterizations}

The experimental approach follows (1) earlier studies of steady-state CFDFs using various nozzle and tubeOJB's, ${ }^{21,29,16,18,36}$ (2) initial studies of the dynamic weakening of CFDFs using the same oscillatory-input $7.2 \mathrm{~mm}$ nozzle-OJB system ${ }^{30,32}$ as the present OOJB system, and (3) Work-in-Progress Poster presentations featuring improved and extended studies of dynamic flame weakening. ${ }^{31,33}$ The present results include four major sets of dynamic extinction data from the gaseous HC-air systems of ethylene, methane, and 64/36 and 15/85 molar mixtures. The FS extinction data, obtained as functions of applied $\mathrm{pk} / \mathrm{pk}$ voltage magnitudes to twin speakerdrivers, were normalized initially by Hot Wire velocity magnitude data for cold dynamic flows. Later on, the FSs were normalized by calibrated Probe Microphone (PM) pressure magnitude data obtained under essentially identical conditions, with the exception that significant flows to speaker diaphragms were applied (5 SLPM) in a second set of PM measurements. Thus the present dynamic flame extinction results were normalized first with pressure oscillation magnitudes at the nozzle exits that "tracked" axially applied velocity magnitudes, and second with steady 
FS limits that scaled the results. The resultant normalizations provided idealized measures of Dynamic Flame Weakening (DFW) effects due to forced oscillations of fuel and air input velocities on the laminar CFDF systems.

The dynamic OOJB system shown in Fig. 1 is actually comprised of several subsystems. ${ }^{21,22,29,30,33}$ First a mass flow-metered gas mixing system delivers fuel mixture to the upper speaker-driver enclosure; this is followed by flow down a $38 \mathrm{~cm}$ tube to the contoured-nozzle exit. Initially the fuel mixture enters the shallow cone-shaped plenum ( $\sim 6-\mathrm{cm}$ high at the center), bounded at the top by a 20-cm diameter polypropylene speaker-driver cone, and below by a machined metal plate. The plate has a $2.5-\mathrm{cm}$ diameter hole, centered on the speaker axis, which is $\mathrm{O}$ ring sealed to a vertically-oriented $2.2-\mathrm{cm}$ i.d. Pyrex tube that extends $38-\mathrm{cm}$ to the nozzle exit. Similarly, mass flow-metered air is delivered through an identical speaker-driver system at the bottom. Thus in each experiment, nearly-uniform-velocity laminar jets of fuel mixture and air are impinged through matched pairs of $7.2 \mathrm{~mm}$ convergent Pyrex nozzles, to form a free-floating flame (after ignition); this flame moves vertically with any transient flow imbalance (hence free floating), and is always kept centered by adjusting flows. The nozzle gap is fixed at two exit diameters. The nozzle area contraction ratio is $\sim 9: 1$ with convergence over $\sim 1$ tube diameter, and each nozzle is slightly "re-curved" near the exit. The resultant plug-flow velocity field, which exhibits a shallow dish-shaped central depression (consistent with numerical predictions by Rolon et al. ${ }^{25}$ ), has been previously characterized using LDV and PIV measurements. ${ }^{21,22}$ The Pyrex nozzles, insulated by blocks of silica foam, are mounted in a rigid ceramic fiber box with three Pyrex windows and a porous top of sintered metal or ceramic fiber. Argon or $\mathrm{N}_{2}$ bath gas, dispersed radially via a jet near the bottom of the box, prevents/inhibits extraneous combustion outside the central impingement region, and thus minimizes adverse flame attachment, buoyancy, and visibility effects. Fuel and air component flows were hand-controlled using micrometer valves, and monitored by calibrated mass flow meters.

\section{B. Steady State Flame Strength Measurements}

To obtain steady-state extinction of a CFDF, the mass flows of fuel mixture and air are slowly increased simultaneously, so the disk flame, located primarily on the airside, is always centered and free-floating. ${ }^{21,22,26-29}$ Manual control of flame centering is monitored visually, and also through a TV display of the schlieren image from a horizontally oriented focusing schlieren system. ${ }^{21}$ Whenever $\mathrm{N}_{2}$-diluted fuels are used, the HC fuel is fixed at a predetermined target rate and $\mathrm{N}_{2}$ is increased; in this case, because metered fuel and diluent flows are blended in a small glass bead mixer, and then pass through a substantial "dead volume" in the fuel speaker plenum and tube/nozzle system, diluent flow is increased very slowly so the drift in mixture composition has sufficient time to reach the nozzle exit. After each extinction (blowoff), or rupture of the (very) flat disk-shaped-flame structure, a residual ring-shaped (torus) flame quickly establishes at a stable location centered near the stagnation point, where the rate of mixing is maximum. Mass flow rates of each component are then recorded.

The global nozzle-area-average jet velocity, $U_{\text {air }}$, is used to evaluate FS at extinction; $U_{\text {air }}$ is calculated from the mass flow of dry "service" air standardized at $273^{\circ} \mathrm{K}$ and $1 \mathrm{~atm}$, and measured nozzle exit diameter, $7.2 \mathrm{~mm}$. The $U_{\text {fuel }}$ is evaluated similarly from component mass flows. Corresponding Reynolds numbers (based on exit diameter) are generally less than 2000 or 1500 , but are not so low that CFDFs are unacceptably thick or non one-dimensional.

To restore the torus ring-like "tribrachial" (or "edge") flame to a disk flame, ${ }^{21,22,26-29}$ respective flows are gradually decreased, so the slowly shrinking ring approaches $\sim 1$ jet diameter near the stagnation surface. At flame restoration the ring suddenly propagates inward and shifts axially (say, $\sim 1 \mathrm{~mm}$ ) to the airside. After flame restoration, another set of extinction/restoration measurements is obtained for replication.

In previous studies of $\mathrm{H}_{2}$-air and $\mathrm{HC}$-air systems, flame restoration was found independent of jet diameter, and a large hysteresis in exit velocity existed between extinction and restoration. ${ }^{21,22,26-29}$ It was concluded that flame restoration occurs as a velocity-limited piloted-reignition along a thin stagnated region containing inter-diffused jet flows; this happens when the inward "stretched laminar burning velocity" finally exceeds the maximum outward radial velocity. ${ }^{29}$ Recent very detailed numerical simulations of flame restoration ${ }^{20,37-39}$ fully support our earlier simplified description. Note, for extinction-restoration hysteresis, the radial strain rate in the central stagnation region must always be smaller than that required for extinction. Otherwise blowoff and restoration will occur at essentially the same flow rates - which was observed, e.g., for methane-air using very small $2.7-\mathrm{mm}$ Tube-OJBs. ${ }^{26}$ Conceivably, flame restoration-like processes could occur in scramjet flameholders.

\section{Dynamic Flame Strength Measurements}

Dynamic extinction measurements were obtained using the same basic flow technique as in the steady-state measurements, except the twin speakers were driven in-phase (always, unless noted) by a series of matched applied voltages, and frequencies. Thus, a waveform generator was first set to a desired frequency and a sinusoidal output of 1-volt amplitude. This became input to a variable speaker-amplifier. Twin analog outputs from the amplifier 
powered the twin speakers. The amplifier outputs were manually adjusted to selected peak-to-peak (pk/pk) voltages while viewing waveform displays on a LeCroy digital oscilloscope. Once the speaker-drivers were set identically, a dynamic Flame Strength measurement was obtained using the same flow procedures discussed above. If flow reversal in the nozzles appeared likely, based on previous hot-wire flow calibrations (described below), and/or the flame was too unstable, based on visual and focusing schlieren observations and also difficulties in maintaining a centered flame, lower $\mathrm{pk} / \mathrm{pk}$ applied voltages were used.

During very early stages of the study ${ }^{30}$ (with Beth Reid in 1998), dynamic extinction measurements were obtained for the $18 \% \mathrm{H}_{2}$-air and $100 \% \mathrm{CH}_{4}$-air systems over a range of pk/pk speaker-driver sinusoidal voltages, at frequencies of 30,60,120 Hz; and later at $25,50,100 \mathrm{~Hz}$. To analyze these dynamic FS data in terms of physically realistic air and fuel input-velocities / strain-rates that effectively characterize extinction limits, independent velocity information at each nozzle exit was needed as a function of applied speaker voltage. (Notably, the very few measurements reported by others ${ }^{3-15}$ of dynamic axial strain rates near the airside flame edge were not of use in the present studies.)

Thus limited Hot-Wire velocimetry measurements of cold flows at the nozzle exits were obtained at three frequencies each, over two distinct time periods. ${ }^{30}$ In each case, pk/pk sinusoidal air and fuel cold-flow input velocity magnitudes were measured at the respective nozzle exits corresponding to various sets of pk/pk speaker voltage magnitudes, steady input mass flows, and applied frequency. The respective Hot-Wire velocity data sets were analyzed using three levels of empirical curve fits. Thus, dynamic extinction data could be transformed and analyzed as functions of pk/pk sinusoidal air and fuel input velocity magnitudes. The velocity magnitudes were deduced as empirical functions of pk/pk speaker voltage magnitudes, mass flow rates of air and fuel, and frequency up to $120 \mathrm{~Hz}$, using a "master" expression for $U_{\text {air }}$ that produced nearly identical results when compared with a second set of independently derived expressions for $U_{\text {air }}$ and $U_{\text {fuel }}{ }^{30}$ (also unpublished data by Clare Mc Namara in 2000 , and by Rachel Johnson in 2001).

Upon combining the dynamic input velocity and extinction data for the $\mathrm{C}_{2} \mathrm{H}_{4} / \mathrm{N}_{2}$-air systems, it was found, for any given raw (uncorrected) $\mathrm{C}_{2} \mathrm{H}_{4}$ mass flow, i.e., 3,5 , or $8 \mathrm{SLPM}$, the measured flame strength, $U_{\text {air, }}$ was a linear decreasing function of the $\mathrm{pk} / \mathrm{pk}$ velocity magnitude of the sinusoidal input, $\mathrm{pk} / \mathrm{pk} U_{\mathrm{air}}$. The resultant negative slopes of these data were a function of frequency, but they also varied with the respective input mass flow rates of $\mathrm{C}_{2} \mathrm{H}_{4}$. Subsequently, slope variations for the three different input mass flows of $\mathrm{C}_{2} \mathrm{H}_{4}$ were effectively "normalizedout" using corresponding steady-state flame strengths of $\mathrm{C}_{2} \mathrm{H}_{4} / \mathrm{N}_{2}$-air, to produce a singular Dynamic Flame Weakening (DFW) response for the $\mathrm{C}_{2} \mathrm{H}_{4} / \mathrm{N}_{2}$-air systems; detailed in Results section.

Errors in extinction limits stemmed from various sources; and some were compensated-for internally. For example, according to the ideal gas law, absolute jet velocities at constant mass flow vary linearly with input temperature. Hence, mass inflow measurements remain unaffected by local variations in gas velocity caused by jet temperature variations; resultant "density-weighted" extinction limits have been found nearly independent of such linear variations in gas velocity up to $\sim 600 \mathrm{~K} .^{29,40}$ Thus potential data scatter due to temperature variation is effectively nullified, which is especially helpful when heated fuel jets are required. ${ }^{27}$ However, variations in atmospheric pressure do affect the data slightly. These have not been routinely accounted-for until quite recently, ${ }^{41}$ where $U_{\text {air }}$ calculated at $300 \mathrm{~K}$ is now routinely multiplied by the ratio $((29.92 \mathrm{in} \mathrm{Hg}) /(\text { Barometric Pressure, in } \mathrm{Hg}))^{3}$. Although the same nozzle-OJB was used throughout this study, on an absolute basis the calculated jet exit velocities are sensitive to (measured) jet diameter squared, and strain rates are sensitive to jet diameter cubed. This can be important when results are compared from different-size OJBs.

\section{Results}

\section{A. Steady Flame Strength}

Steady extinction results for $\mathrm{N}_{2}$-diluted $\mathrm{C}_{2} \mathrm{H}_{4}$ vs. air CFDFs, Fig. 2, exhibit a large variation in FS with input $\mathrm{C}_{2} \mathrm{H}_{4}$ mole fraction. A minor extrapolation of the asymptotic data trend (previously well-established ${ }^{21,22,26-29}$ ) indicates a FS of $310 \mathrm{~cm} / \mathrm{s}$ for $100 \% \mathrm{C}_{2} \mathrm{H}_{4}$-air flames (at $273 \mathrm{~K}$ ). This corresponds to an ASR of $430 \mathrm{1} / \mathrm{s}$ at $273 \mathrm{~K}$, and $473 \mathrm{1} / \mathrm{s}$ at $300 \mathrm{~K}$. The asymptote represents an extinction limit that is unaffected by fuel diffusion rate from the stagnation point, but is still limited by molecular diffusion of other species throughout the flame, and by chemical kinetics. The indicated raw $\mathrm{C}_{2} \mathrm{H}_{4}$ inputs, in uncorrected Standard Liters per Minute (SLPM), do not contain a Flow Meter Factor of 0.58 for ethylene mass flow that is otherwise applied to all calculated quantities.

The steady-state FS for $100 \% \mathrm{C}_{2} \mathrm{H}_{4}$ can be compared with the author's early measurements for $100 \% \mathrm{CH}_{4}$ and $18 \% \mathrm{H}_{2}$ CFDFs obtained using the same $7.2 \mathrm{~mm}$ OJB, and also $100 \% \mathrm{H}_{2}$ CFDFs using smaller OJBs. ${ }^{29}$ More recently, the early results were repeated for validation and further characterized, along with other gaseous HCs, using a series of scaled OJBs. ${ }^{16,18,36}$ Based on a number of semi-independent data entries, ${ }^{16,29-31,36}$ the $\mathrm{C}_{2} \mathrm{H}_{4}$-air 
flame averages $\sim 2.7$ times stronger than the $\mathrm{CH}_{4}$ flame. However, the $\mathrm{C}_{2} \mathrm{H}_{4}$ flame is 12 times weaker than the $\mathrm{H}_{2}$ CFDF, based on extensive $100 \% \mathrm{H}_{2}$ results ${ }^{29}$ that were subsequently replicated and assessed. ${ }^{16,18}$

\section{B. Dynamic FS, and Data Transformations using Hot-Wire Velocimetry of Cold Flows}

Fig. 3 shows some wide-ranging dynamic FS extinction results for ethylene, as an extension of the steady results in Fig. 2. It represents about $200 \mathrm{C}_{2} \mathrm{H}_{4} / \mathrm{N}_{2}$ vs air measurements made early in the program. Various sinusoidal speaker-voltage input magnitudes, $\mathrm{pk} / \mathrm{pk} v$, were used to produce corresponding axial exit velocity magnitudes, $\mathrm{pk} / \mathrm{pk} U_{\text {air, }}$ at preset frequencies. For certain mid-range frequencies, the data show significant adverse impacts of oscillatory velocity inputs on dynamic FS (up to a factor of 2), over a wide range of raw $\mathrm{C}_{2} \mathrm{H}_{4}$ inputs (1-8 SLPM) and resultant $\mathrm{C}_{2} \mathrm{H}_{4} / \mathrm{N}_{2}$ input mole fractions. At frequencies of 500 to $1600 \mathrm{~Hz}$ there was very little effect of input oscillations on flame strength, compared to $0 \mathrm{~Hz}$ (steady-state). At very low frequencies (i.e., 4 and $10 \mathrm{~Hz}$ ) a small but measureable degree of dynamic weakening was still evident (but hard to see with all the overlay in Fig. 3).

Fig. 4 exemplifies an early attempt using Hot Wire velocimetry data (later shown inadequate) to analyze the dynamic FS extinction data for $\mathrm{C}_{2} \mathrm{H}_{4} / \mathrm{N}_{2}$ CFDFs based on 3 SLPM (raw) $\mathrm{C}_{2} \mathrm{H}_{4}$ input flows. The analysis attempted to quantify the effects of sinusoidal pk/pk voltage magnitudes to the twin speakers on resultant sinusoidal pk/pk exit velocity magnitudes. The abscissa is based on a detailed empirical analysis of Hot Wire data ${ }^{30,31}$ obtained up to 120 $\mathrm{Hz}$ on nozzle exit flows, and then an extrapolation of the empirical pk/pk exit velocity magnitude function to higher frequencies $(500 \mathrm{~Hz})$.

The Fig. 4 data analyses apply over a middle to upper range of frequencies (100-500) in which the weakening effects on FS grow linearly with the empirically calculated pk/pk $U_{\text {air }}$ magnitudes of velocity oscillation, but the slopes vary unevenly with frequency. The data at both 100 and $200 \mathrm{~Hz}$ show the dynamic response of FS to pk/pk $U_{\text {air }}$ remained linear, even though some peak velocities were quite large compared with the mean $U_{\text {air- }}$ Checks at other flows and frequencies indicated similar linear responses, even while approaching local flow reversal (which can occur, based on HW data traces, but was carefully avoided).

Thus the linear slopes in Fig. 4, which applied at designated frequencies and were well defined in numerous similar plots, were used in conjunction with measured $\mathrm{pk} / \mathrm{pk}$ speaker voltages and a corresponding empirically calculated pk/pk $U_{\text {air }}$ exit velocity data function to define a "Dynamic Velocity Response" of FS, described below.

Fig. 5 summarizes the resultant "Dynamic Velocity Response" of Flame Strength that was obtained from the 200 early-on measurements of $\mathrm{C}_{2} \mathrm{H}_{4} / \mathrm{N}_{2}$-air extinction, and was based on the empirically derived $\mathrm{pk} / \mathrm{pk} U_{\text {air }}$ velocity magnitude projections from Hot Wire data (but extrapolated beyond $120 \mathrm{~Hz}$ ). Because the respective data sets for 3 , 5 , and $8 \mathrm{SLPM} \mathrm{C}_{2} \mathrm{H}_{4}$ exhibited very similar trends, data averaging was used to define the effect of frequency more clearly. The 4 and $10 \mathrm{~Hz}$ data "appeared" to be reasonably close to steady behavior, so that molecular / free-radical transport processes were "possibly" fast enough to follow relatively slow oscillations in input flow rate (strain rate). At higher frequencies, the flames appeared to weaken gradually as the (negative) "Dynamic Velocity Response" increased slowly until, just beyond $250 \mathrm{~Hz}$, it increased steeply, by a factor of four, as the flame became much weaker. And finally at slightly higher frequencies, a very steep recovery occurred between 450 and $500 \mathrm{~Hz}$, which appeared to terminate the extensive weakening, indicating a high-frequency cut-off limit. The reproducibility of these extinction data was remarkably good at fixed frequencies (typically $\pm 3 \%$ ), and even at highly sensitive frequencies, e.g. $475 \mathrm{~Hz}$. At frequencies above $500 \mathrm{~Hz}$, the CFDFs were minimally responsive, and tended asymptotically to become totally unresponsive with respect to input velocity perturbations and extinction.

By this point in the study, the existence of significant acoustic resonance effects in the data / system had became quite clear. The large and abrupt changes in Dynamic Velocity Response around the "notch" region in Fig. 5 indicated that major resonance phenomena occurred; and additional waviness in the spline fits suggested that secondary resonance phenomena were also present.

A simple calculation helped define some possible resonances. The 38-cm length of Pyrex tube to each nozzle exit, plus $\sim 6-\mathrm{cm}$ of dead space between the tube and the speaker diaphragm in the plenum region, coincided with $1 / 2$ wavelength of sound at $395 \mathrm{~Hz}$ and 1 wavelength at $790 \mathrm{~Hz}(=(348 \mathrm{~m} / \mathrm{s}) /(0.44 \mathrm{~m})$. These resonances could promote some destructive interference at $395 \mathrm{~Hz}$, and major constructive interference at $790 \mathrm{~Hz}$, within each speaker-tube system. Although large obvious changes in sound intensity and flame weakening were initially noted and accepted as "experimental facts of life" when frequency was changed at fixed applied speaker voltages, and it was obvious that a sound measurement survey was needed, implications of the apparent resonance did not become clear until the results of the PM survey were examined.

\section{Probe Microphone (PM) Measurements}

A wide-frequency-range calibrated Probe Microphone system, with a $1 \mathrm{~mm}$ i.d., $50 \mathrm{~mm}$ long probe was used to measure the localized sound pressure field at the air (and fuel) nozzle exits as a function of frequency. This was 
done first without flows, and later with fixed flows of 5 SLPM $\mathbf{N}_{2}$. The idea behind the initial PM measurements at zero flow ${ }^{30,32}$ was to characterize resonance phenomena in the absence of extraneous flow perturbations, and thus provide a quantitative basis for characterizing dynamic flame response. Later it was recognized that the dynamics of the speaker diaphragms, and corresponding sound pressure measurements, were sensitive to the positive pressures of gas flowing through the speaker plenums to the respective nozzles located downstream. Notably, this had already been seen during earlier Hot Wire velocity calibration measurements.

Both sets of results in Fig. 6 show substantial effects of acoustic resonance in the system, equivalent to constructive interference for $2,1,1 / 2$, and $1 / 3$ wavelengths. And Fig. 6 also shows that significant differences in acoustic pressure existed, at both low and middle frequencies, between PM data obtained with zero flows and fixed flows of 5 SLPM $\mathrm{N}_{2}$. More detailed tests conducted at key frequencies, and with flows of $\mathrm{N}_{2}$ between 0 and 8 SLPM (not shown), indicated that most of the acoustic pressure differences occurred when gas flows varied from zero to relatively low SLPMs. Thus the detailed data obtained at 5 SLPM adequately represented the entire experimental range of flows encountered.

Finally while it was recognized that, for a high degree of rigor, the Euler Equation for sound propagation might be solved numerically, using appropriate boundary conditions in our confined system to obtain corresponding oscillating exit velocity fields, this level of analysis was not attempted. Instead, we reasoned that $\mathrm{pk} / \mathrm{pk} U_{\text {air }}$ input magnitudes are directly derivable from measured acoustic pressure magnitudes, $\mathrm{pk} / \mathrm{pk} P$, within the central region of interest, based on application of the basic Euler Equation to (essentially) unbounded flow fields, where a speed-ofsound proportionality factor relates the two quantities, (pk/pk) $U_{\mathrm{air}}$ and $(\mathrm{pk} / \mathrm{pk}) P$. Thus the measured $\mathrm{pk} / \mathrm{pk} P$ serves as a surrogate for $\mathrm{pk} / \mathrm{pk} U_{\mathrm{air}}$.

\section{Transformation of Dynamic Extinction Data using PM Measurements}

Fig. 7 shows the same dynamic extinction data for 3 SLPM ethylene as in Fig. 3, except the new abscissa is measured $\mathrm{pk} / \mathrm{pk} P$, or sinusoidal pressure magnitude at the air nozzle exit based on zero cold flows. The results are similarly linear at each frequency, and thus slopes denoted as "Dynamic Pressure Response" are defined. Since no evidence of significant non-linearity was found in the complete dynamic extinction data set, all the data could be analyzed (as before) as a function of frequency.

As a final step, the same dynamic extinction data shown for 3 SLPM ethylene in Figs. 3 and 7 are corrected in Fig. 8 as a function of $\mathrm{pk} / \mathrm{pk} P$ based on 5 SLPM flows. The resultant corrected dynamic pressure response slopes in Fig. 8 were subsequently coupled with numerous other slope results from similar data plots (not shown), and finally assessed as a function of frequency. As with the initial analysis using PM data based on zero cold flows, the originally observed "notch" in the dynamic-velocity-response data (Fig. 5) continued to be entirely absent as a result of normalizing the dynamic extinction data using PM data based on 5 SLPM flows.

In summary, for the remainder of this paper, the dynamic FS extinction results are normalized using the independently obtained sound pressure measurements, $\mathrm{pk} / \mathrm{pk} P$, over wide ranging frequencies, instead of attempting to link the FS results to frequency-limited hot-wire velocity magnitudes. To minimize the observed diaphragmpressurization bias while still retaining analytic simplicity, we used the "5 SLPM flow" sound-pressure magnitude data exclusively. Also, we did not attempt to transform the $\mathrm{pk} / \mathrm{pk}$ pressure oscillations to $\mathrm{pk} / \mathrm{pk}$ velocity oscillations for a freely propagating wave, or for a more complex internal acoustic flowfield, even though we recognize that diffusion flame extinction is caused by local velocity oscillations, not pressure variations. Thus the measured calibrated $\mathrm{pk} / \mathrm{pk}$ pressure oscillations are now used as "surrogates" for the $\mathrm{pk} / \mathrm{pk}$ velocity oscillations that cause extinction.

At this point we turn first to the entire set of dynamic FS extinction results for the $\mathrm{C}_{2} \mathrm{H}_{4} / \mathrm{N}_{2}$-air system, based on 3,5 , and $8 \mathrm{SLPM} \mathrm{C}_{2} \mathrm{H}_{4}$ flows, in order to "baseline" the dynamic FSs of the systems.

\section{E. Refinement of the Flame Response Function for the $\mathrm{C}_{2} \mathrm{H}_{4} / \mathrm{N}_{2}-$ Air System}

Once the entire set of dynamic Flame Strength data for the $\mathrm{C}_{2} \mathrm{H}_{4} / \mathrm{N}_{2}$-air system was normalized and reanalyzed to obtain linear slopes as a function of pk/pk pressure magnitude, based on the 5 SLPM PM calibration data, a plot of the raw (un-normalized) Dynamic Flame Weakening data could be examined in Fig. 9, as a function of frequency. Several important features are evident. First the respective raw DFW data for the three different ethylene flow rates exhibit significant differences, especially in the 8 to $50 \mathrm{~Hz}$ range. This suggests the results might be normalized by steady-state Flame Strength to collapse the data to a singular function (discussed below). Second, a fairly well defined plateau region of quasi-steady responses appears to exist at frequencies up to $20 \mathrm{~Hz}$. Third, a mid-frequency fall-off transition is evident. And fourth, an apparent "high-frequency" cutoff beyond $200 \mathrm{~Hz}$ is followed by an asymptotic approach to "complete insensitivity" at frequencies from $300 \mathrm{~Hz}$ to $1600 \mathrm{~Hz}$, the limit of this study. 
Finally, the former "notch" in dynamic-velocity-response data disappeared entirely as a result of normalizing the dynamic Flame Strength data with PM pressure data.

Fig. 10 shows the final reduction of the raw DFW results in Fig. 9 after they were normalized by steady-state Flame Strengths, for respective ethylene mass flows of 3, 5, and 8 SLPM $\left(U_{\text {air,ss }}=210.8,256.4\right.$, and $289.6 \mathrm{~cm} / \mathrm{s}$ at $273 \mathrm{~K}$ ). Additionally, the results were multiplied by one hundred to define percentages of Dynamic Flame Weakening per unit pk/pk pressure magnitude (Pa). Thus the raw DFW results in Fig. 9 collapsed to a single curve in Fig. 10, which characterizes an ethylene response independent of its mole fraction in mixtures with $\mathrm{N}_{2}$. Note that DFW data in the 8 to $50 \mathrm{~Hz}$ range were most affected, followed by a substantial reduction of "data scatter" at higher frequencies for the respective ethylene mass flows. The resultant normalized data now represent a respectably large range of steady state Flame Strengths and ethylene mole fractions.

\section{F. Normalized DFW of CFDFs based on Methane, 64/36 and 15/85 Surrogate Mixtures, and Ethylene}

Fig. 11 shows an inclusive plot of all the normalized Dynamic Flame Weakening results for ethylene, methane, and the two surrogate $\mathrm{HC}$ mixtures used in this study, for frequencies of $8 \mathrm{~Hz}$ and higher. The upper and lower bounding results clearly illustrate our earlier finding that methane flames are weakened to a much greater extent than ethylene flames at frequencies of $100 \mathrm{~Hz}$ and less. The two $\mathrm{HC}$ mixture results exhibit intermediate behavior, but appear preferentially influenced by the molar ethylene content in each mixture. Also, the "knee like" transitions from extinctions at low frequencies, to abrupt "progressive strengthening" of flames in the "falloff" region, also occurs at slightly higher frequencies as the fuel changes from pure methane to pure ethylene. (Notably, falloffs in average flame temperature were analyzed by Egolfopoulos and Campbe $11^{11}$ using an approach analogous to one defined in "Stokes' Second Problem," - that characterizes the attenuation of momentum oscillations by diffusion.) Because all the data are normalized with respect to steady-state Flame Strengths (e.g., $U_{\text {air,ss }}$ for ethylene is $2.7 x$ that for methane), the absolute differences in Flame Response between ethylene and methane are somewhat smaller.

An intriguing question that arises from examining Fig. 11 is "what DFW extinction behavior should be expected at zero $\mathrm{Hz}$, and up to, say, 8 or $10 \mathrm{~Hz}$ ?" Experimentally, it became increasingly difficult to impart controlled, but not excessive oscillations to flames, to produce extinctions at frequencies below $10 \mathrm{~Hz}$ without driving the flames against the fuel and air nozzles - in which case a CFDF could no longer be characterized as unanchored and freefloating. However, it was also recognized that idealized DFWs at frequencies close to zero $\mathrm{Hz}$, with any reasonable amplitude of forced oscillation, should be zero if one considers the limiting properties of "steady-state" flames. Therefore it was reasoned that DFW could be set to zero at $0 \mathrm{~Hz}$ for each fuel, and synthetic linear transitions could be drawn to apparent maximum value DFWs (e.g. at 8 or $10 \mathrm{~Hz}$ ) that reflected "reasonable" average quasi-steady maximum values for each fuel system.

Thus Fig. 12 shows a modified plot of the same DFW data sets used in Fig. 11, but with (1) a linear frequency scale, (2) smooth weighted-average fits of imposed linear transitions in "synthetic DFW data" from 0 to 8 (or 10) $\mathrm{Hz}$, and (3) smooth weighted-average fits of DFW data from 10 to $300 \mathrm{~Hz}$ (with a scale terminated at $200 \mathrm{~Hz}$ ). Note the 15/85 and 64/36 mixture data represent 3-point "ladder" averages, from 8 to $28 \mathrm{~Hz}$, of extinction data obtained in triplicate. Fig. 13 shows the same results as Fig. 12, but with a scale terminated at $100 \mathrm{~Hz}$ to improve clarity at low frequencies.

Based on all the results in Figs. 11, 12 and 13, the extent of DFW is significant for all four HC-air systems up to a practical high frequency limit of about $150 \mathrm{~Hz}$, beyond which DFW asymptotically approaches zero, and the flames become totally insensitive out to $600 \mathrm{~Hz}$. For very low frequencies up to $8 \mathrm{~Hz}$, it was not possible to achieve DFW measurements. However, since DFW $=0$ was effectively measured at $0 \mathrm{~Hz}$, and DFW demonstrably increased to measured quasi-steady values at 8 (or 10) Hz, it became clear that "classically expected" transient diffusion lags within the oscillating flame were affecting the low frequency results, and appeared significant. For frequencies beyond 8 to $10 \mathrm{~Hz}$, measured DFW responses "appeared" to attain significant near-quasi-steady "plateau" values at frequencies ranging from below, say 15, to as high as $30 \mathrm{~Hz}$. After attaining reasonably welldefined peak values and near-plateaus, DFW always reached a point of rapid decrease for each fuel (i.e., the flames got stronger), in which the flames became progressively less responsive to higher frequencies -- where it is believed that internal phase lags became inconsequential and the flames became insensitive to oscillating diffusive transport.

To provide a better analytic comparison of the DFW falloff region, exponential decay fits of the DFW data were obtained from 10 to $300 \mathrm{~Hz}$. Fig. 14 shows the resultant fits from 10 to $200 \mathrm{~Hz}$. Although plotted data for the mixtures suggest more complex intermediate transitions may have occurred, the exponential decay fits provide the best known analytic representations of fundamental decays in flame dynamic weakening (flame strengthening) that occurred as the flames became progressively less responsive at higher frequencies.

Based on the exponential decay data fits in Fig. 14, Fig. 15 shows resultant empirical fits of the relative DFW of methane, and the 15/85 and 64/36 (\% ethylene/\% methane) surrogate HC fuel mixtures, compared to ethylene, from 
10 to $150 \mathrm{~Hz}$. The plotted DFW (HC) / DFW $\left(\mathrm{C}_{2} \mathrm{H}_{4}\right)$ data ratios for the two surrogates are substantially lower than the respective "molar proportioning" curves, where the relative DFWs for methane and ethylene are linearly weighted by the mole fraction of each component. Based on the comparisons, the respective ethylene contents of the surrogate fuels have a disproportionately favorable effect on reducing flame weakening (i.e., strengthening) of the non-premixed CFDFs. Thus, as a practicality, the substitution of ethylene for methane in a fuel mix offers an additional degree of stability against oscillatory instabilities at frequencies up to $\sim 150 \mathrm{~Hz}$.

\section{G. Implications for Scramjet Combustors}

Possible implications of the idealized dynamic results for near-atmospheric combustion in scramjets (and other low pressure systems with combustion instabilities) are difficult to quantify, considering the substantial complexity of flameholding in scramjets; e.g., see an earlier review of facility test effects on flameholding. ${ }^{34,35}$ One approach for scramjets is to consider fundamental resonant frequencies in cavity-related pressure oscillations caused by ducted supersonic flows, and resultant turbulent shear layer flows, over both open and closed cavities. ${ }^{42}$ For example, application of a "modified Rossiter" expression, reviewed in Ref. 42, predicts a fundamental frequency of $2960 \mathrm{~Hz}$ for a typical free stream air velocity of $1500 \mathrm{~m} / \mathrm{s}$ over an open cavity of $10-\mathrm{cm}$. length. Because this frequency is considerably beyond the applicable range for non-premixed hydrocarbon-air extinction, such induced oscillations may not affect open-cavity-based flameholding in this case. Nevertheless, careful acoustic measurements and more detailed analyses of flameholding in various fueled cavities and subsonic wake flows, especially in the vicinity of possibly-oscillating fuel jets, are needed to fully assess the potential for flame weakening effects in both test engines and flight vehicles.

\section{Summary of Findings}

Extensive dynamic-extinction "Flame Strength" (FS) measurements were obtained on unanchored (free-floating) laminar Counter Flow Diffusion Flames (CFDFs), stabilized by steady input flows and perturbed by superimposed in-phase sinusoidal velocity inputs at the fuel and air nozzle exits. Results for pure ethylene and methane fuels "bounded" respective intermediate dynamic FSs for 64/36 and 15/85 mole-percent gaseous surrogate fuel mixtures. The 64/36 mix was previously recommended to mimic both the ignition characteristics and FS of vaporized and cracked JP-7 "like" kerosene for a HIFiRE scramjet; the 15/85 mix was found to mimic the FS of un-cracked JP-7 "like" fuel. The present study includes new steady state and dynamic results, and significantly refined data analysis methodology, compared with the author's previous Dynamic FS paper. ${ }^{32}$

Both limited Hot-Wire (HW) measurements of velocity fluctuation magnitudes at the nozzle exits, and much more extensive and accurate Probe Microphone (PM) measurements of acoustic pressure magnitudes at the same locations, were used to analyze the Dynamic FS data. It was important to use PM measurements obtained when significant gas flows were occurring, because each speaker diaphragm is positively pressurized by flowing fuel and air during normal run conditions with speaker-imposed oscillations.

The "quasi steady" and dynamic CFDF extinction measurements in this study, coupled with the dynamic coldflow PM calibrations at the nozzle exits, led to the following findings and conclusions:

(1) The $0 \mathrm{~Hz}$ (steady) FS for pure $\mathrm{C}_{2} \mathrm{H}_{4}$ is directly relatable to $\mathrm{FSs}$ for $\mathrm{CH}_{4}$ and $18 \% \mathrm{H}_{2}$ CFDFs obtained using the same $7.2 \mathrm{~mm}$ OJB, and $100 \% \mathrm{H}_{2}$ CFDFs characterized earlier using scaled OJBs. Based on highly reproducible global measurements, linked in multiple ways to the local axial input strain rate for extinction of a $\mathrm{CH}_{4}$ flame at 300 $\mathrm{K}(\sim 400 \mathrm{1} / \mathrm{s})$, the $\mathrm{C}_{2} \mathrm{H}_{4}$ flame is $\sim 2.7$ times stronger. And yet, based on replicated $\mathrm{H}_{2}$-air results, the $\mathrm{C}_{2} \mathrm{H}_{4}$ flame is 12 times weaker than a $100 \% \mathrm{H}_{2} \mathrm{CFDF}$.

(2) The $\mathrm{HC}$-air dynamic flame weakening results are fundamentally consistent with limited published results on the structure and extinction (rare) of forced unsteady CFDFs. Available numerical simulations and sparse data indicate transient diffusive responses of key species (e.g., $\mathrm{H}$-atom, $\mathrm{O}, \mathrm{OH}, \mathrm{H}_{2}$, and $\mathrm{HC}$ radicals) affect phase lags (relative to inputs) in concentration and temperature waves, which tend to weaken a flame at frequencies near $10 \mathrm{~Hz}$. At higher frequencies, rate-limited diffusive responses ultimately cause flame insensitivity, with no weakening.

(3) Dynamic FS varied linearly with pk/pk $U_{\text {air }}$ (velocity magnitude, HW), and also $\mathrm{pk} / \mathrm{pk} P$ (pressure magnitude, PM) at nozzle exits. A complete set of PM cold-flow measurements led to the effective normalization and removal of "excess" weakening in Dynamic FS at particular frequencies due to apparatus-based acoustic resonances. The Dynamic FS data were further normalized by $0 \mathrm{~Hz}$ (steady) FS, which effectively removed differences due to $\mathrm{N}_{2}$ dilution of $\mathrm{C}_{2} \mathrm{H}_{4}$. Thus Dynamic Flame Weakening (DFW) could be defined as $\%$ decrease in FS per Pascal of pk/pk $P$ oscillation, namely, DFW $=-100 \mathrm{~d}\left(U_{\text {air }} / U_{\text {air, }, 0 \mathrm{~Hz}}\right) / \mathrm{d}(\mathrm{pkpk} P)$. 
(4): It is now recognized that, consistent with measurements of steady extinction, DFW must first increase from 0 , at $0 \mathrm{~Hz}$, to achieve the near-maximum values that were typically measured at frequencies near $10 \mathrm{~Hz}$. Thus linear increases to these near-maximums at 8 or $10 \mathrm{~Hz}$ were hypothesized and used to represent the initial rise of DFW for all four HC fuels. (Note that unpublished results for pure ethane, propane, propylene, and butane also showed the same behavior.) A maximum in DFW occurred over a relatively narrow frequency range $(8-15 \mathrm{~Hz})$ for methane, where $\mathrm{DFW}_{\max }=45$ (\% weakening)/Pa; but the $\mathrm{C}_{2} \mathrm{H}_{4} / \mathrm{N}_{2}$ system tended to "plateau" from 8 to $\sim 25 \mathrm{~Hz}$, where $\mathrm{DFW}_{\max }$ was nearly constant at $9.4 \pm 0.2 \% / \mathrm{Pa}$, and was independent of $\mathrm{C}_{2} \mathrm{H}_{4} / \mathrm{N}_{2}$ mole fraction. Maximum DFWs for the $15 / 85$ and $64 / 36$ surrogates were intermediate at $\sim 24$ and $\sim 18 \% / \mathrm{Pa}$, respectively. Thus we characterize the respective maxima as reflecting maximally weakened non-premixed diffusion flame structures that are highly perturbed by acoustically induced $\mathrm{d} U_{\text {air }} / \mathrm{d} P$ oscillations in the airside (and fuelside) input axial velocity gradients.

(5) Beginning at $\sim 25 \mathrm{~Hz}$ and then continuing to $\sim 150 \mathrm{~Hz}$, the $\mathrm{C}_{2} \mathrm{H}_{4} / \mathrm{N}_{2}$ flames weakened progressively less (i.e. strengthened) and became asymptotically insensitive (DFW $\sim 0$ ) at $\sim 300 \mathrm{~Hz}$, which continued beyond $600 \mathrm{~Hz}$. The DFW of $\mathrm{CH}_{4}$ flames followed a similar pattern, but descended from much greater weakening than ethylene flames. Notably the $\mathrm{DFW}_{\max }$ for $\mathrm{CH}_{4}$ was $4.8 \mathrm{x}$ larger, even though the $0 \mathrm{~Hz}$ steady-state FS was only $2.7 \mathrm{x}$ smaller. With increasing frequency, the DFWs for the 15/85 and 64/36 surrogates decayed from their maxima at intermediate rates that maintained approximate proportionality beyond $100 \mathrm{~Hz}$.

In summary, the above-described DFW responses increased rapidly from 0 at $0 \mathrm{~Hz}$ to achieve near-maximum weakening at 8 to $10 \mathrm{~Hz}$. Thus methane, and every other gaseous fuel investigated (ethane, propane, propylene, and butane; unpublished results), achieved a reasonably well-defined maximum and then began to decay, whereas ethylene achieved a broad maximum (plateau) and didn't begin significant decay until after $25 \mathrm{~Hz}$. At higher frequencies, DFW decreased progressively, reflecting a characteristic re-strengthening of each flame as internal phase lags and reductions in transient diffusive transport became increasingly less effective in weakening the flames. A practical high- $f$ limit for DFW was effectively $\sim 150 \mathrm{~Hz}$, beyond which the flames became essentially insensitive to input flow oscillations beyond $600 \mathrm{~Hz}$.

\section{Conclusions}

The Dynamic Flame Weakening limits are unique to the combustion kinetics and diffusion rates for each fuel, and significantly different from steady extinction limits, for all the non-premixed fuel vs. air systems studied (including unpublished results on four other $\mathrm{HCs}$ ). Methane and ethylene results effectively bound the response of intermediate $15 / 85$ and $64 / 36$ ethylene/methane surrogates that respectively mimic the FS of un-cracked and cracked JP-7 "like" fuels. The DFW maxima correlate inversely and non-linearly with steady-state FSs. And because the dynamic weakening of methane flames tends to be much greater than for ethylene flames, up to about $150 \mathrm{~Hz}$, methane is clearly a less desirable fuel in the presence of significant low frequency oscillations or instabilities.

With particular regard to scramjet applications, we conclude the fundamental results of this study can be applied at least indirectly to airbreathing scramjet engines. For example, critical early stages of localized subsonic flameholding and potential flameout can be influenced strongly by both upstream and cavity-based fuel injection processes that "feed" recirculation zones having "sufficient" residence-time distribution. Important transient phenomena that may contribute to flameout potential include acoustic resonance in cavity flameholders due to interactions of cavity edges with shock waves and over-riding supersonic flows; near-field coupling with fuelinjector wakes and subsonic vortex shedding; and dynamic coupling with unsteady fuel injection flows. Nonpremixed cavity flames that may be near extinction will be weakened further or extinguished by dynamic straining (or stretching) processes at certain frequencies that cause fluctuating diffusion of reactive species in "laminarflamelet-like" reaction zones. Because such transient effects may cause the loss of "robust" flameholding, and possibly flameout, it seems important to characterize suspected dynamic effects and assess their potentials for occurrence in scramjet and other combustor designs. Furthermore, attempts to reduce high frequency oscillations at the expense of increasing low frequency instabilities may increase the likelihood of flameout due to the higher sensitivities of non-premixed flame extinction at low frequencies. Logically, it seems important that careful measurements are made at low frequencies to assess possible effects of localized acoustic fields on critical flameholding in ground-based and flight tests of scramjet engine configurations.

Finally, one general finding for the planned HIFiRE demonstration experiments is that the $64 \% / 36 \%$ surrogate, which has the same steady Flame Strength as an independently proposed tertiary surrogate for cracked JP-7 "like" fuel, exhibits a disproportionately high Dynamic Flame Strength that reflects the exceptional properties of ethylene, relative to other hydrocarbons. Thus, the possibility of inadvertent loss of scramjet flameholding (flameout) due to unanticipated low frequency oscillations is most likely reduced as a consequence of the unique properties of ethylene in the surrogate. 


\section{References}

${ }^{1}$ Clarke, J.F., and Stegen, G.R., "Some Unsteady Motions of a Diffusion Flame Sheet," J. Fluid Mech., 34: part 2, 1968, pp. 343-358.

${ }^{2}$ Saitoh, T., and Otsuks, Y., "Unsteady Behavior of Diffusion Flames and Premixed Flames for Counter Flow Geometry," Comb. Sci. Tech. 12: 1976, pp. 135-146.

${ }^{3}$ Stahl, G., and Warnatz, J., "Numerical Investigation of Time-Dependent Properties and Extinction of Strained Methane- and Propane-Air Flamelets," Combust. Flame, 85: 1991, pp. 285-299.

${ }^{4}$ Ghoniem, A.F., Soteriou, M.C., and Knio, O.M., "Effect of Steady and Periodic Strain on Unsteady Flamelet Combustion," Twenty-Fourth Symposium (International) on Combustion, The Combustion Institute, 1992, pp. 223-230.

${ }^{5}$ Darabiha, N., "Transient Behavior of Laminar Counterflow Hydrogen-Air Diffusion Flames with Complex Chemistry," Comb. Sci. Tech., 86: 163-181 (1992).

${ }^{6} \mathrm{Kim}$, J.S. and Williams, F.A., "Contribution of Strained Diffusion Flames to Acoustic Pressure Response," Combust. Flame, 98: 1994, pp. 279-299.

${ }^{7}$ Egolfopoulos, F.N., "Dynamics and Structure of Unsteady, Strained, Laminar Premixed Flames, Twenty-Fifth Symposium (International) on Combustion, The Combustion Institute,1994, pp. 1365-1373.

${ }^{8} \mathrm{Im}$, H.G, Bechtold, J.K. and Law, C.K., "Counterflow Diffusion Flames with Unsteady Strain Rates," AIAA Paper 95-0128, Jan., 1995,9 pp.

${ }^{9} \mathrm{Im}$, H.G., Law, C.K., Kim, J.S. and Williams, F.A., "Response of Counterflow Diffusion Flames to Oscillating Strain Rates," Combust. Flame, 100: 21-30 (1995).

${ }^{10}$ Brown, T.M., and Pitz, R.W., "Experimental Investigation of Counterflow Diffusion Flames with Oscillatory Stretch," AIAA Paper 96-0124, Jan. 1996.

${ }^{11}$ Egolfopoulos, F. and Campbell, C.S., "Unsteady Counterflowing Strained Diffusion Flames: Diffusion-Limited Frequency Response," J. Fluid Mech. 318: 1996, pp. 1-29.

${ }^{12}$ Kistler, J.S., Sung, C.J., Kreutz, T.G., Law, C.K., Nishioka, M., "Extinction of Counterflow Diffusion Flames Under Velocity Oscillations," Twenty-Sixth Symposium (International) on Combustion, The Combustion Institute, 1996, pp. 113-120.

${ }^{13}$ Brown, T.M., Pitz, R.W., and Sung, C.J., "Oscillatory Stretch Effects on the Structure and Extinction of Counterflow Diffusion Flames," Twenty-Seventh Symposium (International) on Combustion, The Combustion Institute, 1998, pp. 703-710.

${ }^{14}$ Decroix, M.E., and Roberts, W.L., "Study of Transient Effects on the Extinction Limits of an Unsteady Counterflow Diffusion Flame," Combust. Sci and Tech.146: 1999, pp. 57-84.

${ }^{15}$ Welle, E.J., Roberts, W.L., Donbar, J.M., Carter, C.D., DeCroix, M.E., "Simultaneous PIV and OH-PLIF Measurements in an Unsteady Counterflow Propane-Air Diffusion Flame," Proceedings of the Combustion Institute, 28, 2001, pp. $2021-2027$.

${ }^{16}$ Pellett, Gerald L., Vaden, Sarah N., Wilson, Lloyd G., "Gaseous Surrogate Hydrocarbons for a HIFiRE Scramjet that Mimic Opposed Jet Extinction Limits for Cracked JP Fuels," Presented at 55 ${ }^{\text {th }}$ JANNAF Propulsion Meeting, 12-16 May, 2008, Boston, MA. JANNAF Paper-847 (2008), 38 pp.

${ }^{17}$ Andac, M.G. and Egolfopoulos, F.N., "Diffusion and Kinetics Effects on the Ignition of Premixed and Non-premixed Flames," Proceedings of the Combustion Institute, 31 (2007), pp. 1165-1172.

${ }^{18}$ Pellett, G.L., Vaden, S.N., and Wilson, L.G., "Opposed Jet Burner Extinction Limits: Simple Mixed Hydrocarbon Scramjet Fuels vs. Air," AIAA Paper 2007-5664, July 2007, 33 pp.

${ }^{19}$ Colket, M.B., III, and Spadaccini, L.J., "Scramjet Fuels Autoignition Study," J. Propulsion and Power, 17, No. 2, 2001, Mar.-Apr. 2001, pp. 315-323.

${ }^{20}$ Hwang, Kyu C., "Two Dimensional Numerical Simulation of Highly-Strained Hydrogen-Air Opposed Jet Laminar Diffusion Flames," Ph. D. Dissertation, Old Dominion University, Norfolk, VA, May 2003.

${ }^{21}$ Pellett, G. L., Roberts, W. L., Wilson, L. G., Humphreys, W. M., Jr., Bartram, S. M., Weinstein, L. M., and Isaac, K. M., "Structure of Hydrogen-Air Counterflow Diffusion Flames Obtained by Focusing Schlieren, Shadowgraph, PIV, Thermometry, and Computation," AIAA Paper 94-2300, June 1994, 23 pp.

${ }^{22}$ Pellett, G. L., Wilson, L. G., Humphreys, W. M.,Jr., Bartram, S. M., Gartrell, L. R., and Isaac, K. M., Roberts, W. L., IV, and Northam, G. B., "Velocity Fields of Axisymmetric Hydrogen-Air Counterflow Diffusion Flames from LDV, PIV, and Numerical Computation," AIAA paper 95-3112, July 1995, 23 pp.

${ }^{23}$ Zambon, A.C, Chelliah, H.K., "Explicit Reduced Reaction Models for Ignition, Flame Propagation, and Extinction of $\mathrm{C}_{2} \mathrm{H}_{4} / \mathrm{CH}_{4} / \mathrm{H}_{2}$ and Air Systems," Combustion and Flame, 150, 2007, pp. 71-91.

${ }^{24}$ Esposito, Gaetano, Sarnacki, Brendyn, and Chelliah, Harsha, "Ignition and Extinction Limits of Strained Ethylene-Air Mixtures: Experimental and computational Study," $6^{\text {th }}$ US Combustion Meeting, Ann Arbor, MI, May, 2009.

${ }^{25}$ Rolon, J.C., Veynante, D., Martin, J.P., and Durst, E., “Counter Jet Stagnation Flows,” Experiments in Fluids, 11, 1991, pp. 313-324.

${ }^{26}$ Pellett, G.L., Northam, G.B., Wilson, L.G., "Counterflow Diffusion Flames of Hydrogen, and Hydrogen Plus Methane, Ethylene, Propane, and Silane, vs. Air: Strain Rates at Extinction," AIAA Paper 91-0370, Jan, 1991, 17 pp.

${ }^{27}$ Pellett, G.L., Northam, G.B., Wilson, L.G., "Strain-Induced Extinction of Hydrogen-Air Counterflow Diffusion Flames: Effects of Steam, $\mathrm{CO}_{2}, \mathrm{~N}_{2}$, and $\mathrm{O}_{2}$ Additives to Air," AIAA Paper 92-0877, Jan., 1992, 15 pp. 
${ }^{28}$ Isaac, K. M., Ho, Y. H., Zhao, J., Pellett, G. L., and Northam, G. B., "Global Characteristics and Structure of Hydrogen-Air Counterflow Diffusion Flames: A One-Dimensional Model," AIAA Paper 94-0680, Jan.,1994. Also, Zhao, J., Isaac, K. M., and Pellett, G. L., J. Propul. Power 12, No. 3: 534-542 (1996).

${ }^{29}$ Pellett, G.L., Isaac, K.M., Humphreys, W.M., Jr., Gartrell, L.R., Roberts, W.L., Dancey, C.L., and Northam, G.B., "Velocity and Thermal Structure, and Strain-Induced Extinction of 14 to 100\% Hydrogen-Air Counterflow Diffusion Flames," Combust. Flame 112, No. 4, 1998, pp. 575-592.

${ }^{30}$ Pellett, G.L., Reid, Beth, McNamara, Clare, Johnson, Rachel, Kabaria, Amy, Panigrahi, Babita, and Wilson, L.G., "Acoustic Weakening of Methane-, Ethylene-, and Hydrogen-Air Counterflow Diffusion Flames, and Implications for Scramjet Flameholding." AIAA Paper 2003-4634, July, 2003, 21 pp.

${ }^{31}$ Pellett, G., Reid, B., McNamara, C., Johnson, R., Kabaria, A., Panigrahi, B., Sammons, K., and Wilson, L., "Dynamic Weakening of $\mathrm{CH}_{4}, \mathrm{C}_{2} \mathrm{H}_{6}$, and $\mathrm{C}_{2} \mathrm{H}_{4} / \mathrm{N}_{2}-$ Air Counterflow Diffusion Flames using Acoustically Perturbed Inflows." Work-inProgress Poster Paper 4F504, Presented at $30^{\text {th }}$ International Symposium on Combustion, Abstracts of Work-In-Progress Posters, The Combustion Institute, Pittsburgh, PA, July 25-30, 2004

${ }^{32}$ Pellett, G.L., Kabaria, A., Panigrahi, B., Sammons, K., Convery, J., and Wilson, L.G., "Dynamic Weakening (Extinction) of Simple Hydrocarbon-Air Counterflow Diffusion Flames by Oscillatory Inflows." AIAA Paper 2005-4332, July 2005, 22 pp.

${ }^{33}$ Pellett, G.L, McNamara, C., Johnson, R., Kabaria, A., Panigrahi, B., Sammons, K., Galgano, J., and Wilson, L.G., "Dynamic Weakening of Gaseous Hydrocarbon (C1-C4)-Air Counterflow Diffusion Flames by Oscillatory Inflows," Work-inProgress Poster Paper 4B01, Presented at $31^{\text {st }}$ International Symposium on Combustion, Abstracts of Work-In-Progress Poster Presentations, The Combustion Institute, Pittsburgh, PA, Aug. 6-11, 2006.

${ }^{34}$ Pellett, G.L., Bruno, C., and Chinitz, W., "Review of Air Vitiation Effects on Scramjet Ignition and Flameholding Combustion Processes," AIAA Paper 2002-3880, July, 2002, 37 pp.

${ }^{35}$ Pellett, G.L., Bruno, C, and Chinitz, W., CHAPTER 4: Air Vitiation Effects on Scramjet Combustion Tests, in Technologies for Propelled Hypersonic Flight, RTO-TR-AVT-007, Volume 2 - Subgroup 4: Scram Propulsion, ISBNs 978-92837-0041-4 / 978-92-837-0041-8, Jan. 2006, pp. 4-1 - 4-21.

${ }^{36}$ Pellett, G.L., Convery, J.L, Wilson, L.G., "Opposed Jet Burner Approach for Characterizing Flameholding Potentials of Hydrocarbon Scramjet Fuels," AIAA Paper 2006-5233, July 2006, 27 pp.

${ }^{37}$ Frouzakis, C.E., Lee, J., Tomboulides, A.G., and Boulouchos, K., "Two-Dimensional Direct Numerical Simulation of Opposed-Jet Hydrogen-Air Diffusion Flame," Twenty-Seventh Symposium (International) on Combustion, The Combustion Institute, 1998, pp. 571-577.

${ }^{38}$ Lee, J., Frouzakis, C.E., and Boulouchos, K., "Two-Dimensional Direct Numerical Simulation of Opposed-Jet HydrogenAir Diffusion Flames: Transition from a Diffusion to an Edge Flame," Proceedings of the Combustion Institute, 28, 2000, pp. 801-806.

${ }^{39}$ Ciani, Andrea, "Hydrogen and Methane Edge and Diffusion Flames in Opposed Jet Configurations: Structure and Stability." Dissertation, submitted to the Swiss Federal Institute of Technology Zurich, Switzerland, for the degree of Doctor of Technical Sciences, Doctoral Thesis ETH No. 16540, 2006, 108 pp.

${ }^{40}$ Pellett, G.L., Isaac, K.M., and Nguyen, G., "Effect of Input Temperature on Strain-Induced Extinction of 50 to $100 \%$ Hydrogen-Air Counterflow Diffusion Flames," Presented at $27^{\text {th }}$ Symposium (International) on Combustion, Abstracts of WorkIn-Progress Poster Presentations, The Combustion Institute, Pittsburgh, PA, Poster W2D01, Aug., 1998, p. 192.

${ }^{41}$ Convery, J.L., Pellett, G.L., O' Brien, W.F., and Wilson, L.G., "An Experimental Study of $n$-Heptane and JP-7 Extinction Limits in an Opposed Jet Burner," AIAA Paper 2005-3766, July, 2005, 8 pp.

${ }^{42}$ Ben-Yakar and Hanson, R.K., "Cavity Flameholders for Ignition and Flame Stabilization in Scramjets: Review and Experimental Study," AIAA Paper 98-3122, July 1998, 17 pp. 


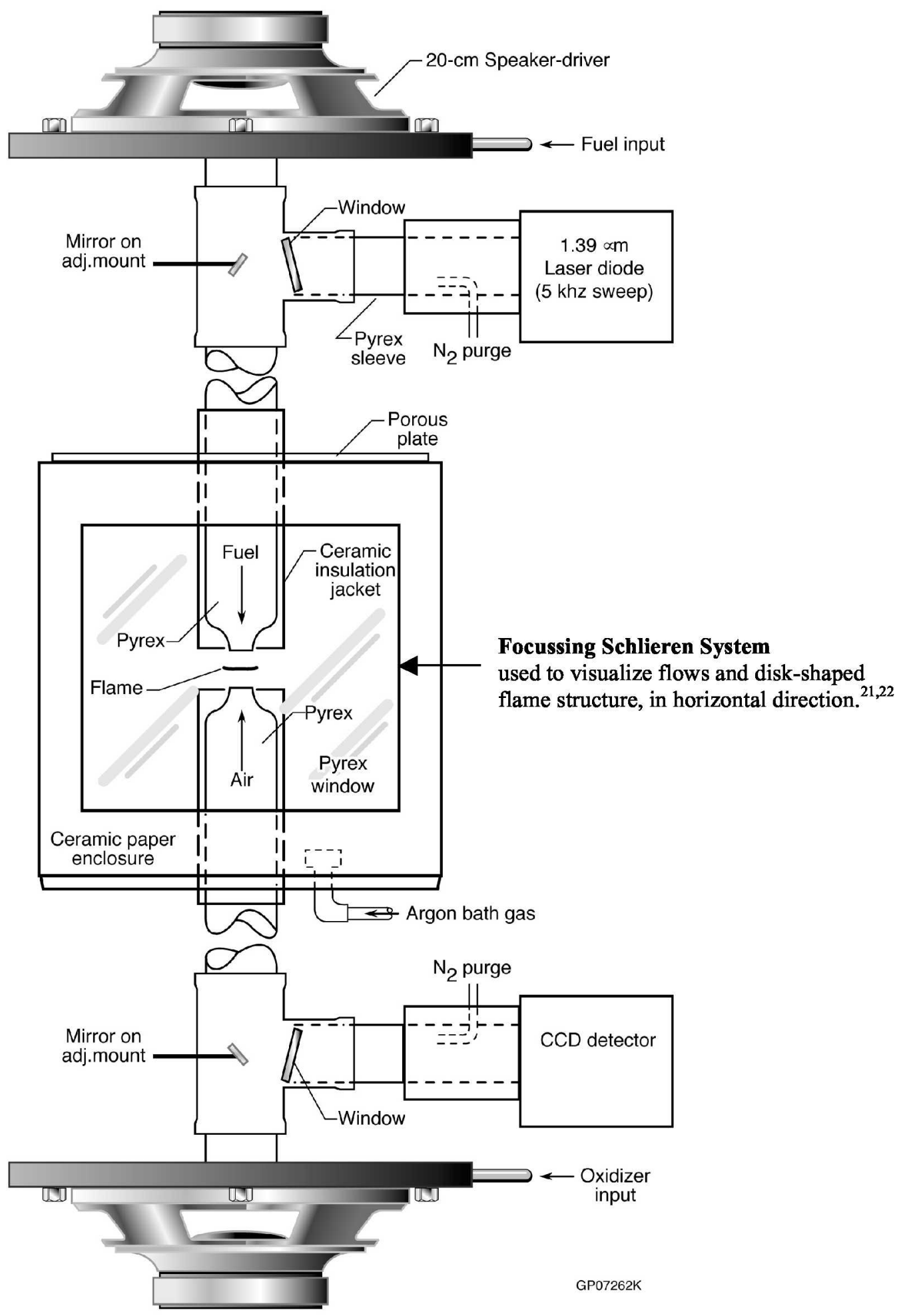

Fig. 1. Schematic of Oscillatory Opposed Jet Burner (OOJB) system showing twin 20-cm speaker-drivers at top (for fuel) and bottom (for air). Diode laser system is passive in this study. 


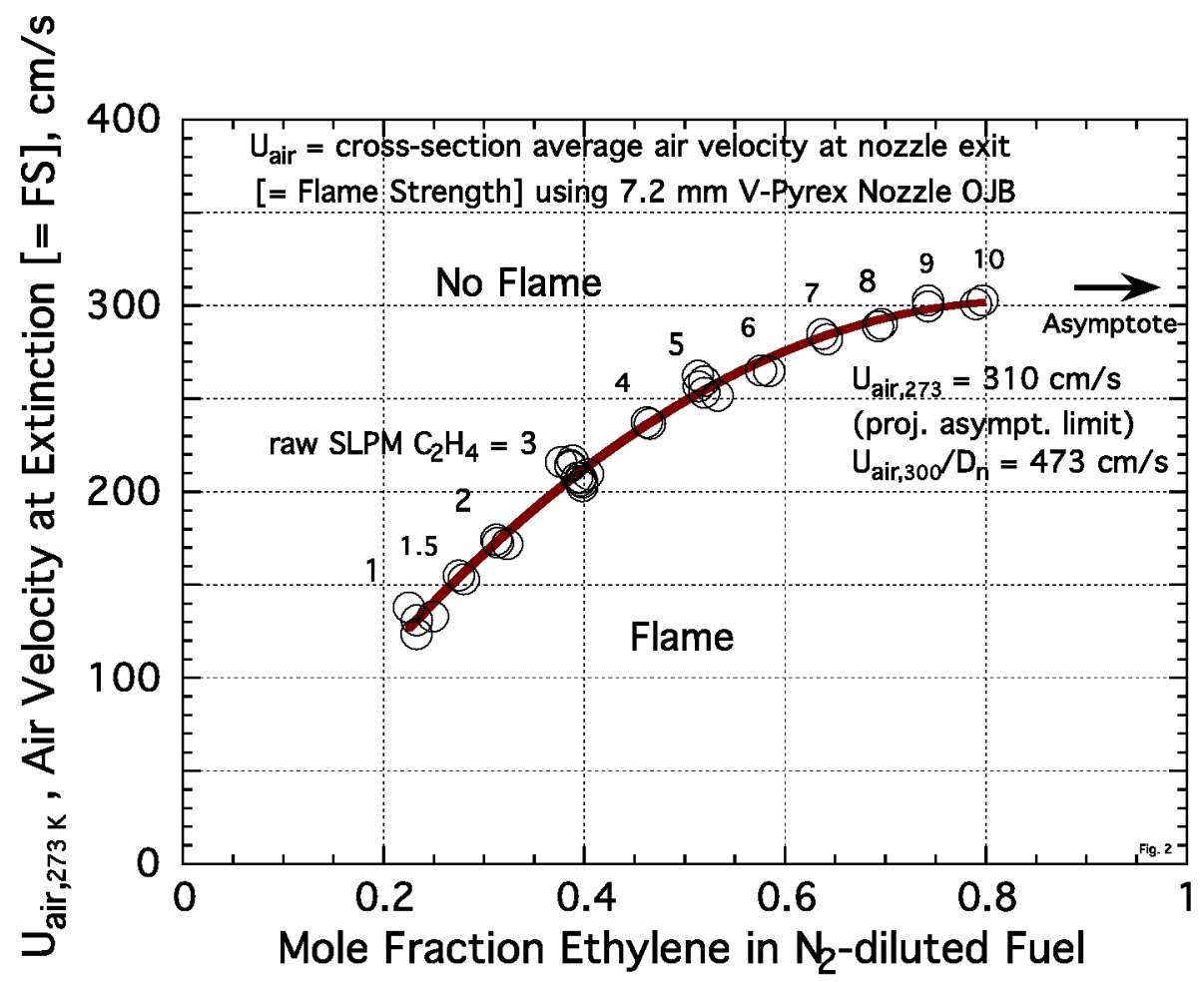

Fig. 2. Flame Strength at steady-state extinction of $\mathrm{C}_{2} \mathrm{H}_{4} / \mathrm{N}_{2}-\mathrm{Air}$ Counter Flow Diffusion Flames (CFDFs), using $7.2 \mathrm{~mm}$ Pyrex Nozzle OOJB. $U_{\text {air }}$ is standardized at $273 \mathrm{~K}, 1 \mathrm{~atm}$.

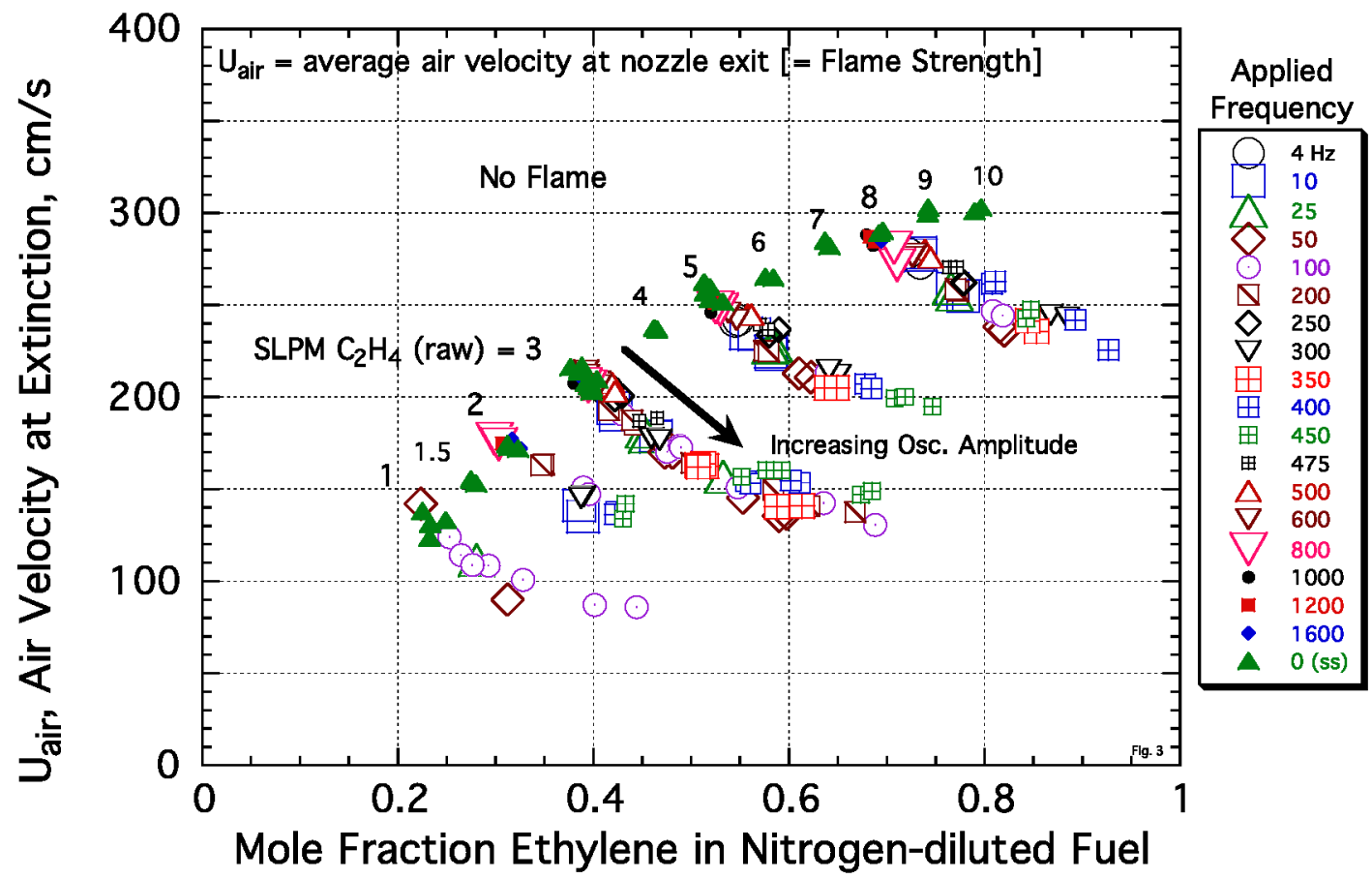

Fig. 3. Steady-state and dynamic extinction of $\mathrm{C}_{2} \mathrm{H}_{4} / \mathrm{N}_{2}$-Air CFDFs, using $7.2 \mathrm{~mm}$ Nozzle OOJB with 1- 10 SLPM $\mathrm{C}_{2} \mathrm{H}_{4}$ Flows, and axially-applied in-phase sinusoidal velocity inputs of $\mathrm{C}_{2} \mathrm{H}_{4} / \mathrm{N}_{2}$ and air at varied amplitude and frequency. Early data up to 11/02 are included here. 


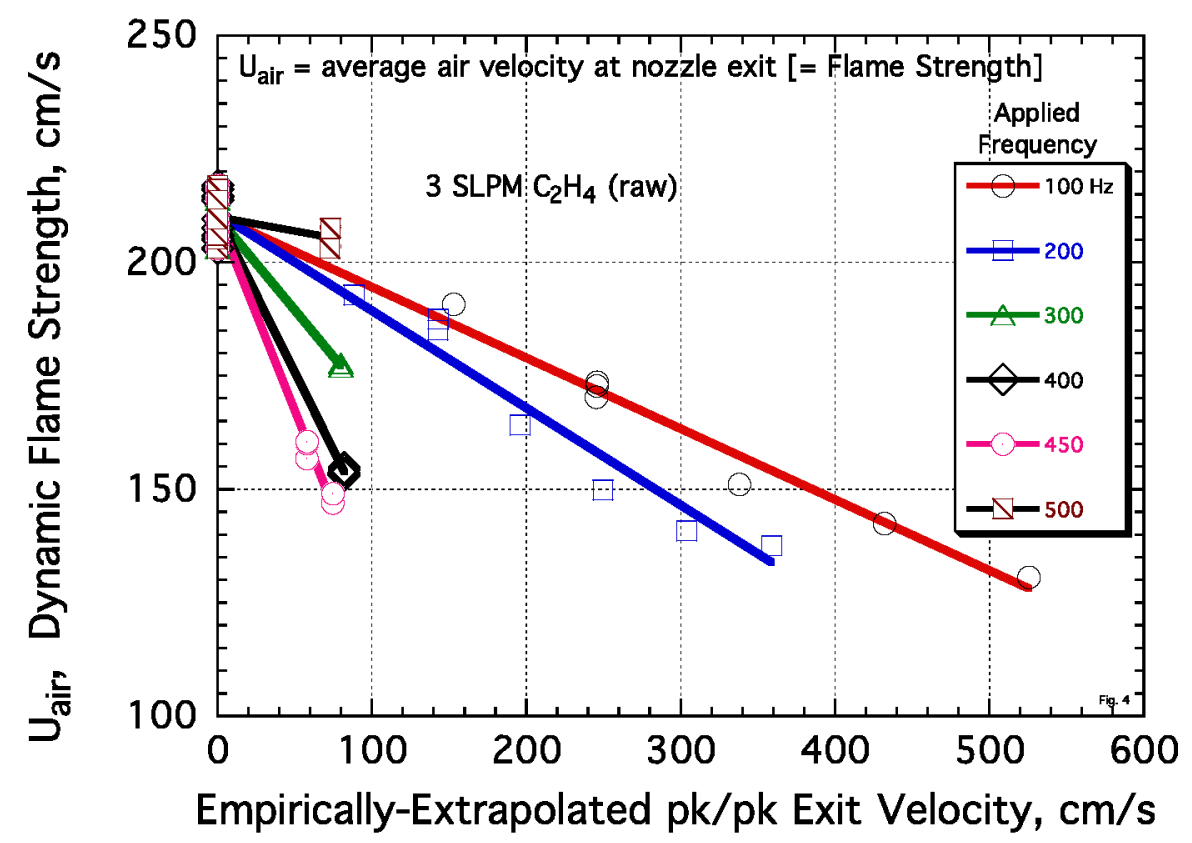

Fig. 4. Dynamic extinction of $\mathrm{C}_{2} \mathrm{H}_{4} / \mathrm{N}_{2}$-Air CFDFs using $7.2 \mathrm{~mm}$ Pyrex nozzle OOJB, with axially-applied in-phase sinusoidal velocity inputs. Abscissa is based on an empirical analysis of Hot-Wire Velocimetry data on nozzle-exit cold-air flows, from $25-120 \mathrm{~Hz}$, and then an extrapolation of the tested empirical pk/pk exit velocity expression to higher frequencies.

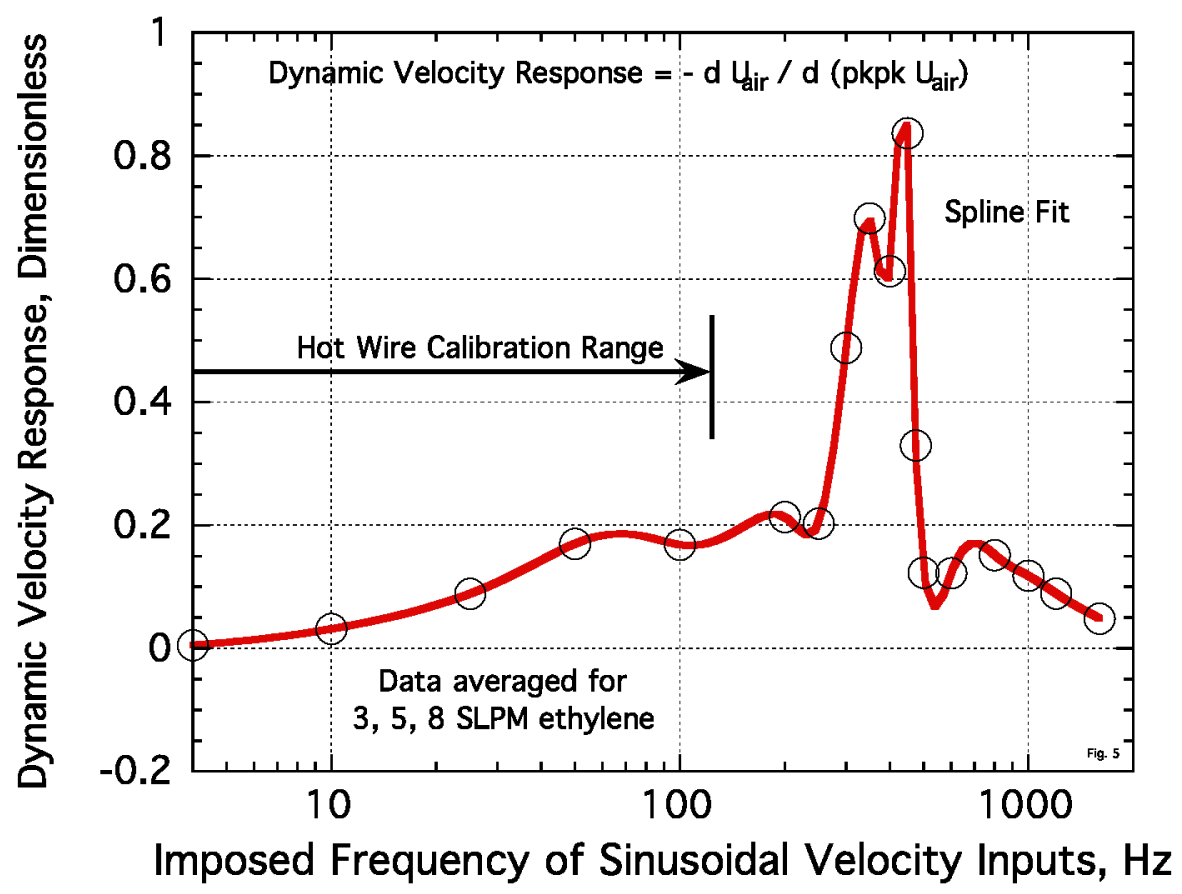

Fig. 5. Dynamic Velocity Response for extinction of $\mathrm{C}_{2} \mathrm{H}_{4} / \mathrm{N}_{2}$-Air CFDFs, using $7.2 \mathrm{~mm}$ Pyrex nozzle OOJB with $3,5,8$ SLPM $\mathrm{C}_{2} \mathrm{H}_{4}$ flows, and axial sinusoidal velocity inputs. Dynamic Velocity Response is based on $\mathrm{pk} / \mathrm{pk}$ nozzle exit air velocities that were originally derived from Hot Wire measurements on cold air and $\mathrm{N}_{2}$ flows at $25-120 \mathrm{~Hz}$, and then empirically projected at higher frequencies. 


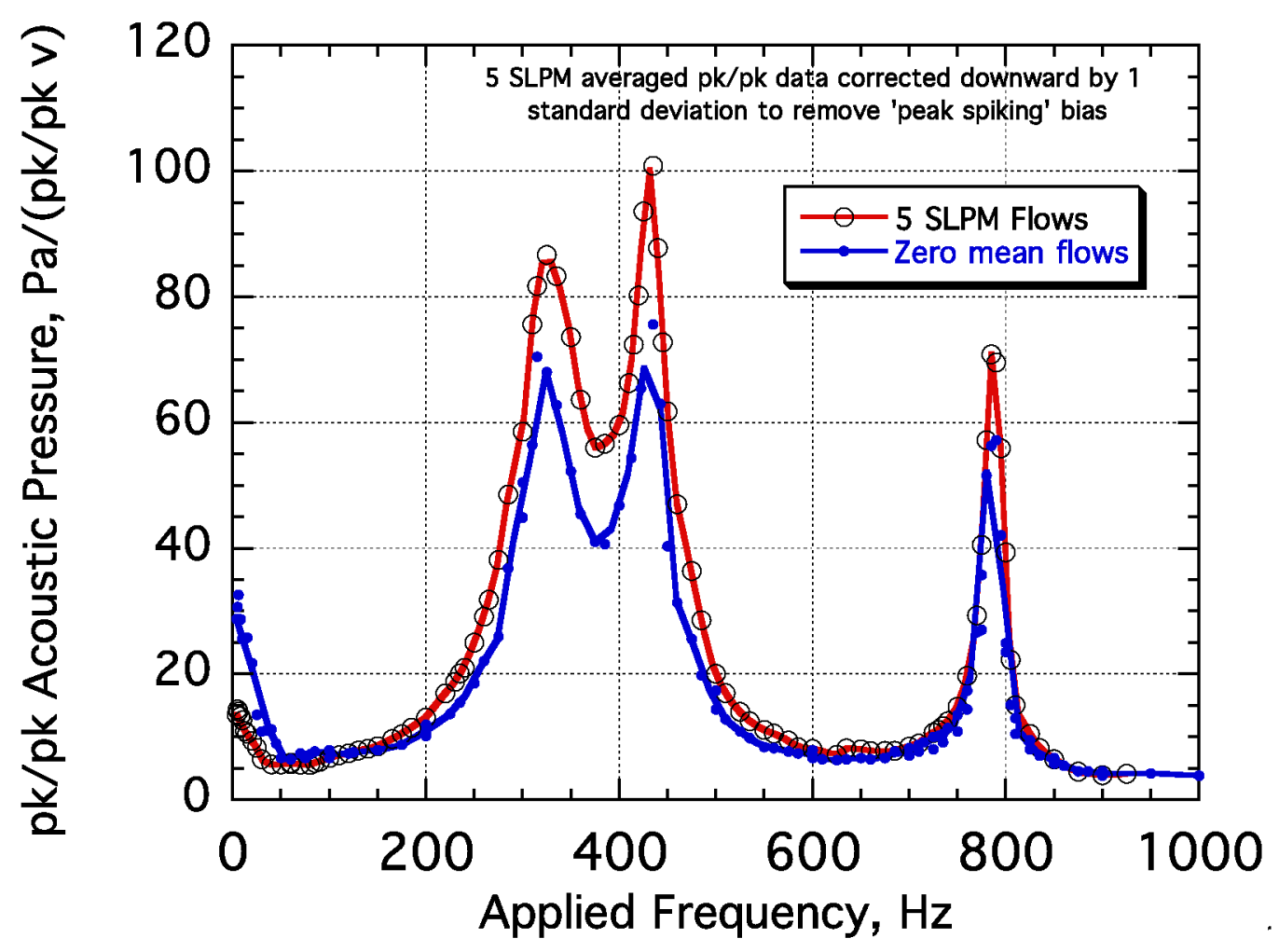

Fig. 6. Normalized Probe Microphone response of sinusoidal speaker-driver sound pressure at exit plane $(\mathrm{r} / \mathrm{a}=0.5)$ of $7.2 \mathrm{~mm}$ Pyrex (air) nozzle, for both 0 and 5 SLPM Air and Fuel flows (air also used for fuel side), using calibrated Probe Microphone with both 50 and $100 \mathrm{~mm}$ long probe tubes. The pk/pk voltage magnitude applied to the speaker-drivers is normalized to 1.0 volt in this calibration. 


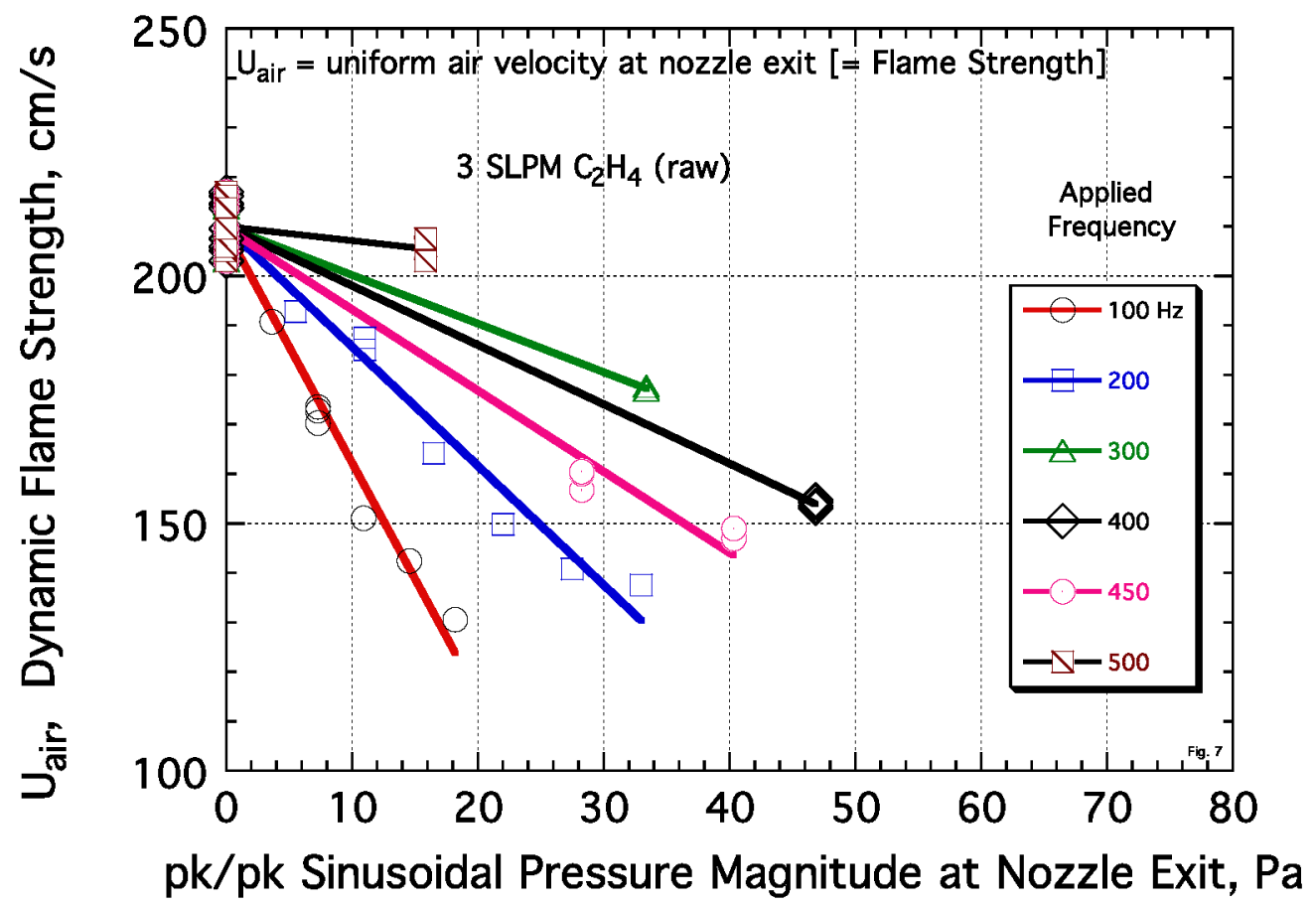

Fig. 7. Dynamic Extinction of $\mathrm{C}_{2} \mathrm{H}_{4} / \mathrm{N}_{2}$-Air CFDFs, for 3 SLPM $\mathrm{C}_{2} \mathrm{H}_{4}$ (raw mass flows), using 7.2 $\mathrm{mm}$ Nozzle OOJB with axially applied sinusoidal velocity inputs. Abscissa is based on Probe Microphone pressure measurements of sound at nozzle exit with zero mean flow, shown in Fig. 6.

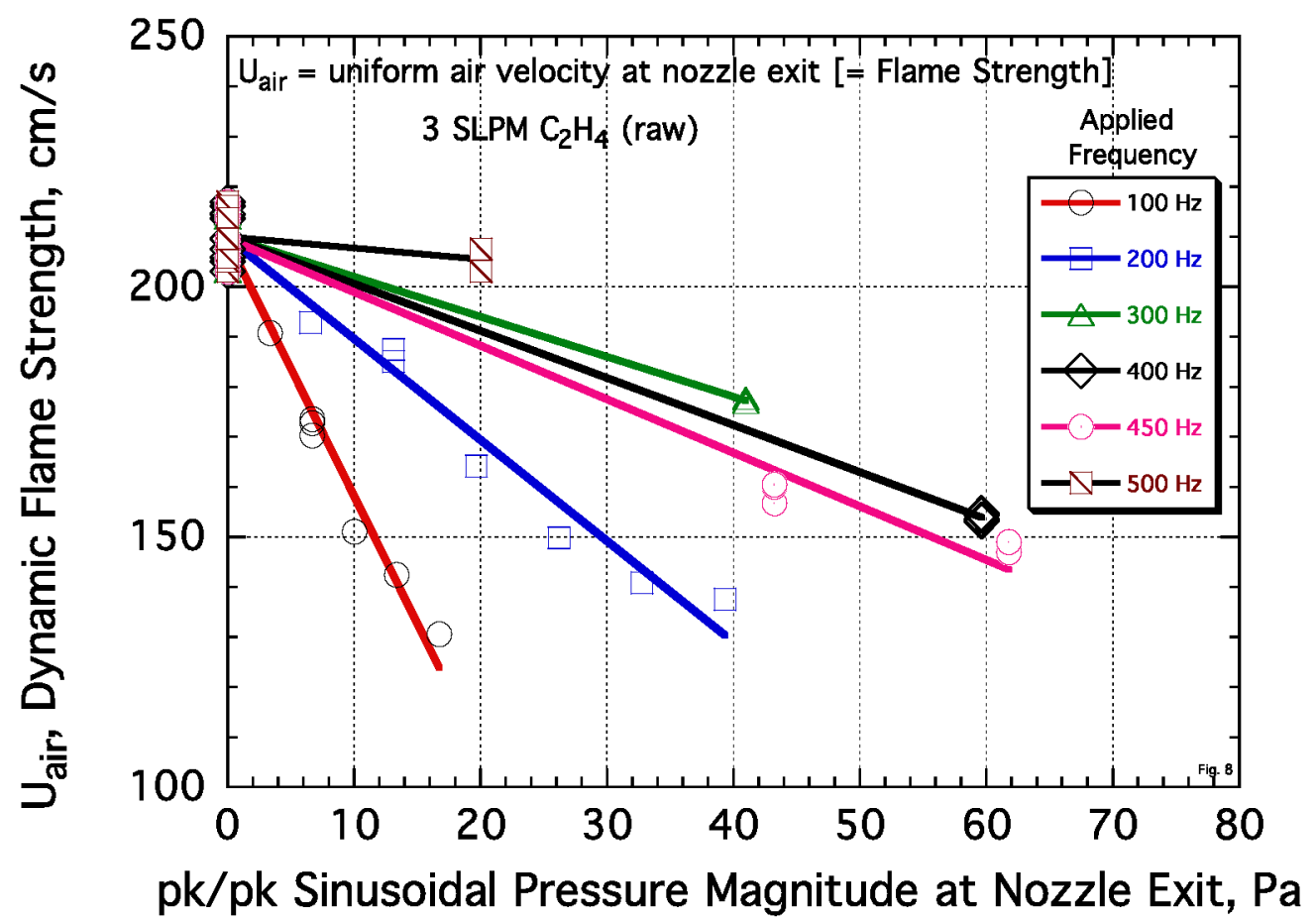

Fig. 8. Dynamic Extinction of $\mathrm{C}_{2} \mathrm{H}_{4} / \mathrm{N}_{2}$-Air CFDFs, for 3 SLPM $\mathrm{C}_{2} \mathrm{H}_{4}$ inputs, using $7.2 \mathrm{~mm}$ Nozzle OOJB with axially applied sinusoidal velocity inputs. Abscissa is based on Probe Microphone pressure measurements of sound at nozzle exit with 5 SLPM flow, shown in Fig. 6. 


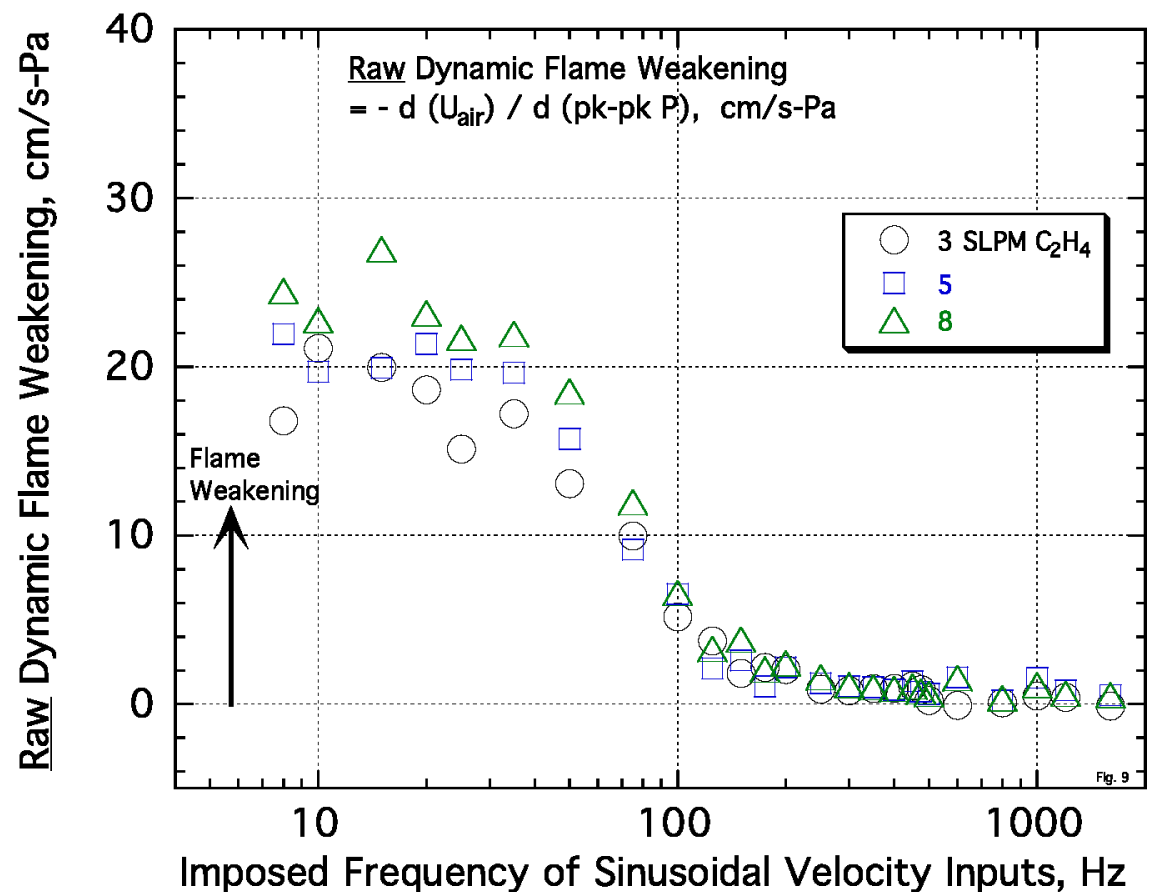

Fig. 9. Raw Dynamic Flame Weakening extinction characteristics of $\mathrm{C}_{2} \mathrm{H}_{4} / \mathrm{N}_{2}$ vs. Air CFDFs, using $7.2 \mathrm{~mm}$ Pyrex Nozzle OOJB, referenced to axially-applied sinusoidal velocity (pressure) Inputs probed by Microphone with 5 SLPM flows.

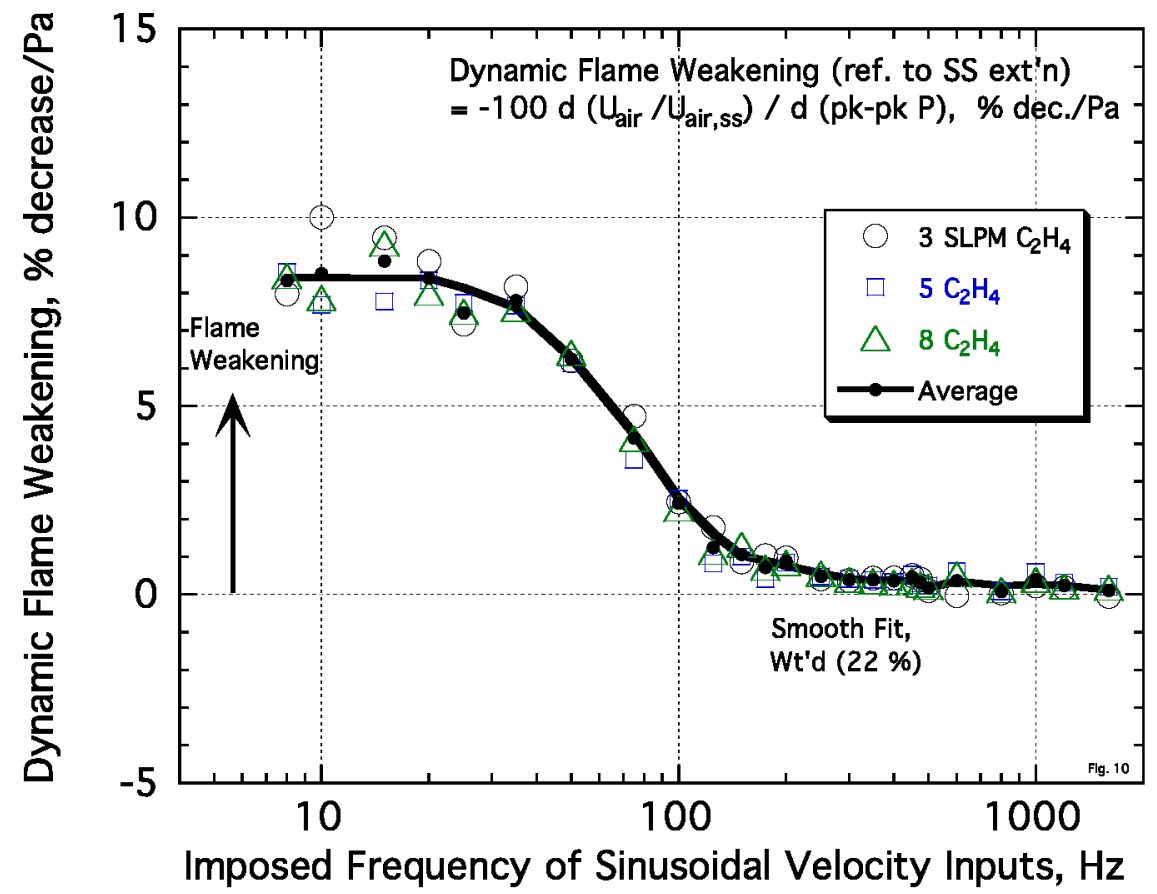

Fig. 10. Fully normalized Dynamic Flame Weakening of $\mathrm{C}_{2} \mathrm{H}_{4} / \mathrm{N}_{2}$-Air CFDFs in Fig. 9, using 7.2 $\mathrm{mm}$ Pyrex Nozzle OOJB and measurements of axially applied sinusoidal velocity inputs probed by Microphone with 5 SLPM flows. Note that normalization collapsed the three sets of ethylene results to an equivalent response that is independent of dilution by $\mathrm{N}_{2}$. 


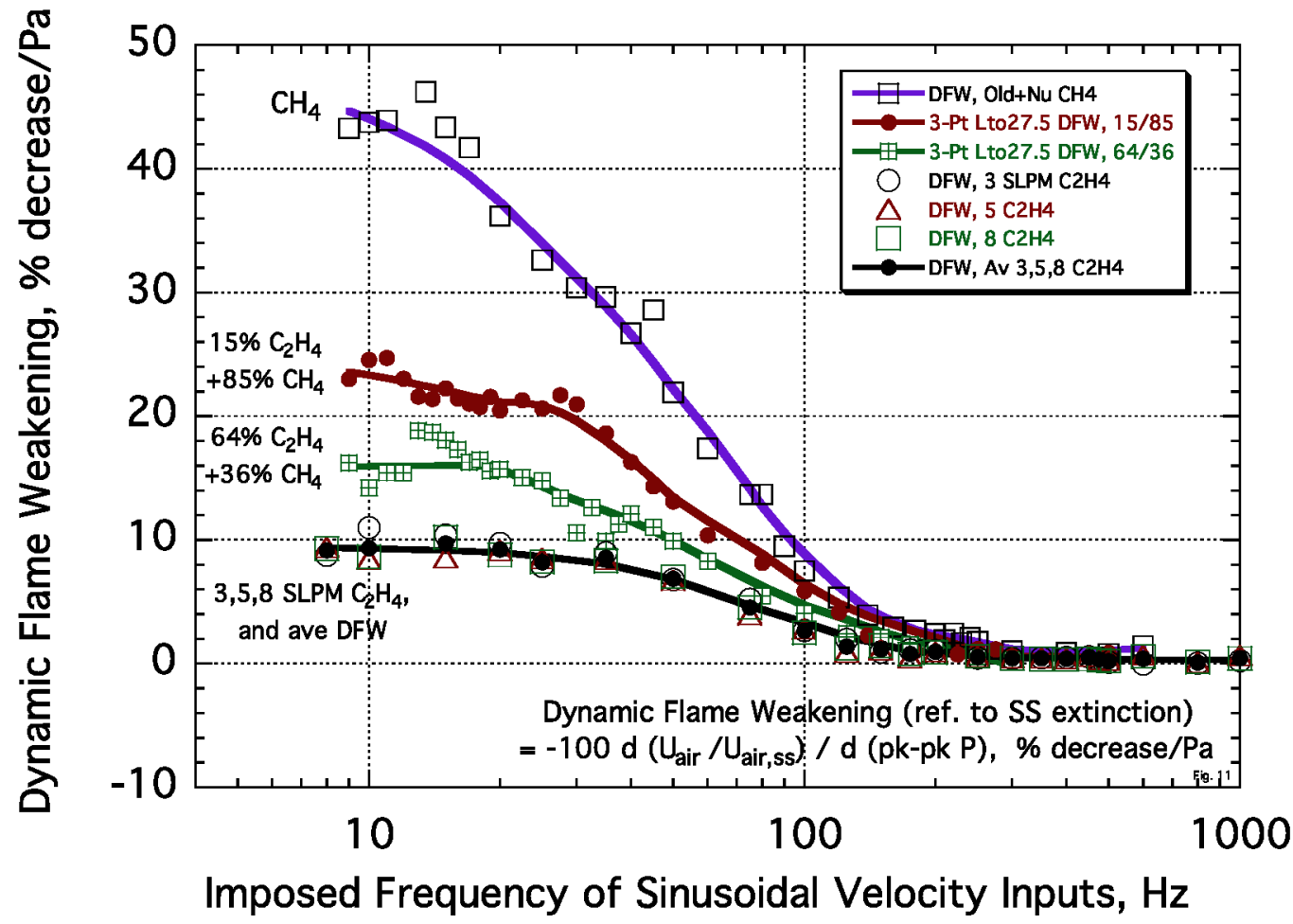

Fig. 11. Early semi-log plot of Dynamic Flame Weakening for all four HC-Air CFDF systems studied (note measured low frequency limits): $\mathrm{C}_{2} \mathrm{H}_{4} / \mathrm{N}_{2}, \mathrm{CH}_{4}$ and $64 / 36$ and $15 / 85$ mole $\%$ ethylene / methane surrogates vs. Air, using $7.2 \mathrm{~mm}$ Pyrex Nozzle OOJB and measurements of axially applied sinusoidal velocity inputs probed by Microphone with 5 SLPM flows. Note the three sets of ethylene results are equivalent, and independent of dilution by $\mathrm{N}_{2}$. 


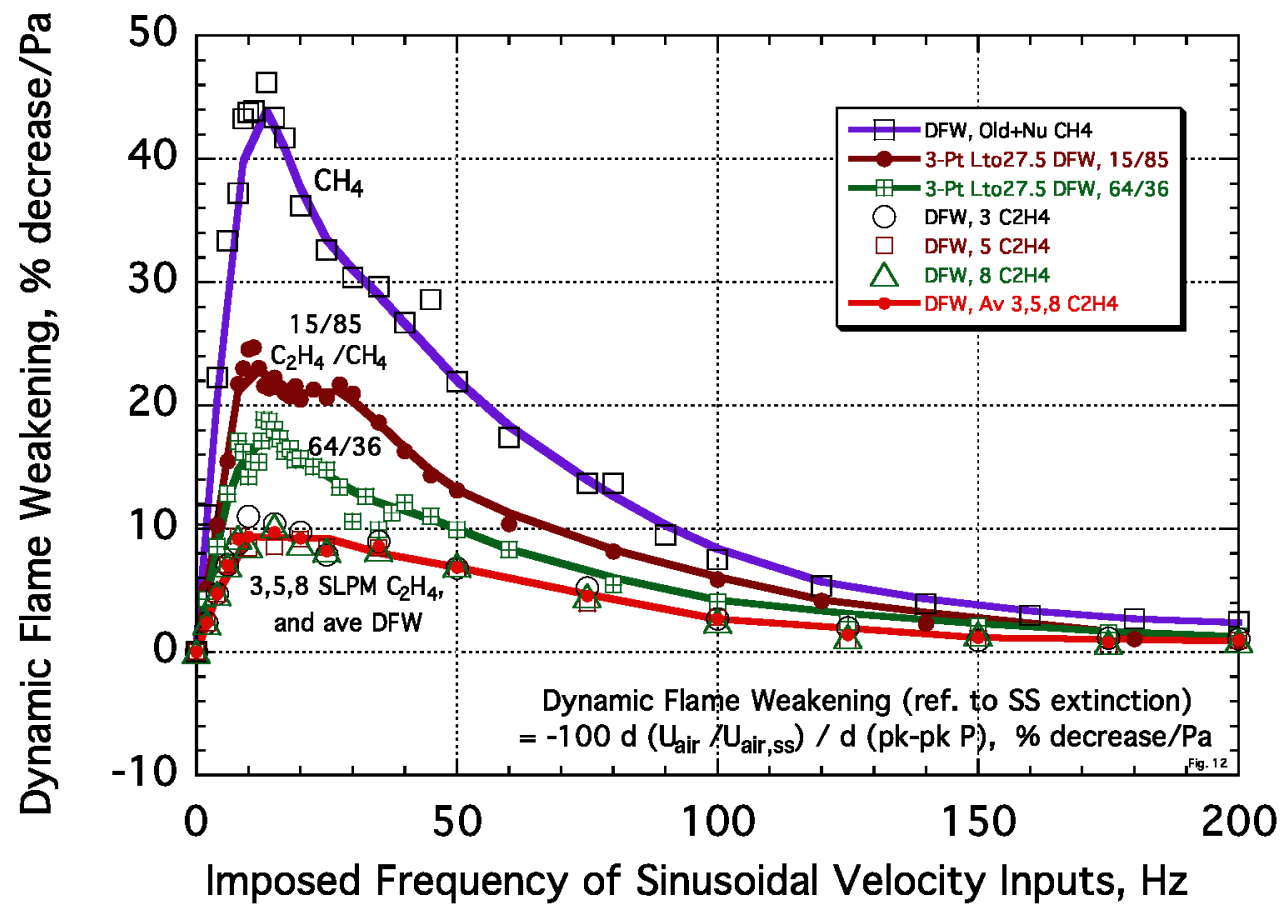

Fig. 12. Dynamic Flame Weakening with linear low-frequency interpolations, for extinction of $\mathrm{C}_{2} \mathrm{H}_{4}, \mathrm{CH}_{4}$, and $64 / 36,15 / 85 \mathrm{C}_{2} \mathrm{H}_{4} / \mathrm{CH}_{4}$ surrogates vs. Air CFDFs, using $7.2 \mathrm{~mm}$ Pyrex Nozzle OOJB and axially-applied sinusoidal velocity (pressure) inputs probed by Microphone (cal @ 5 SLPM).

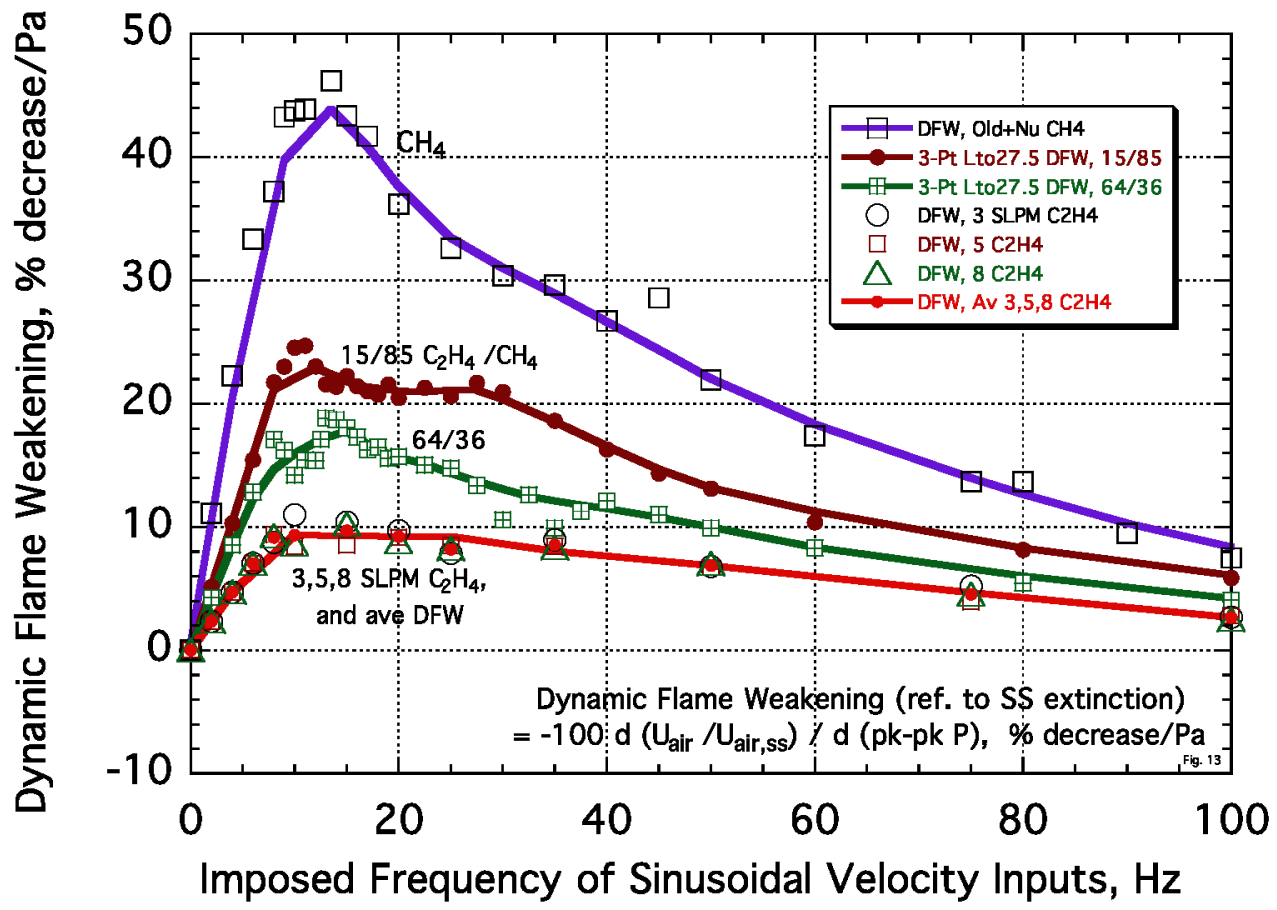

Fig. 13. Dynamic Flame Weakening with linear low-frequency interpolations for extinction of $\mathrm{C}_{2} \mathrm{H}_{4}, \mathrm{CH}_{4}$, and $64 / 36,15 / 85 \mathrm{C}_{2} \mathrm{H}_{4} / \mathrm{CH}_{4}$ surrogates vs. Air CFDFs, using $7.2 \mathrm{~mm}$ Pyrex Nozzle OOJB and axially-applied sinusoidal velocity (pressure) inputs probed by Microphone (cal @ 5 SLPM). 


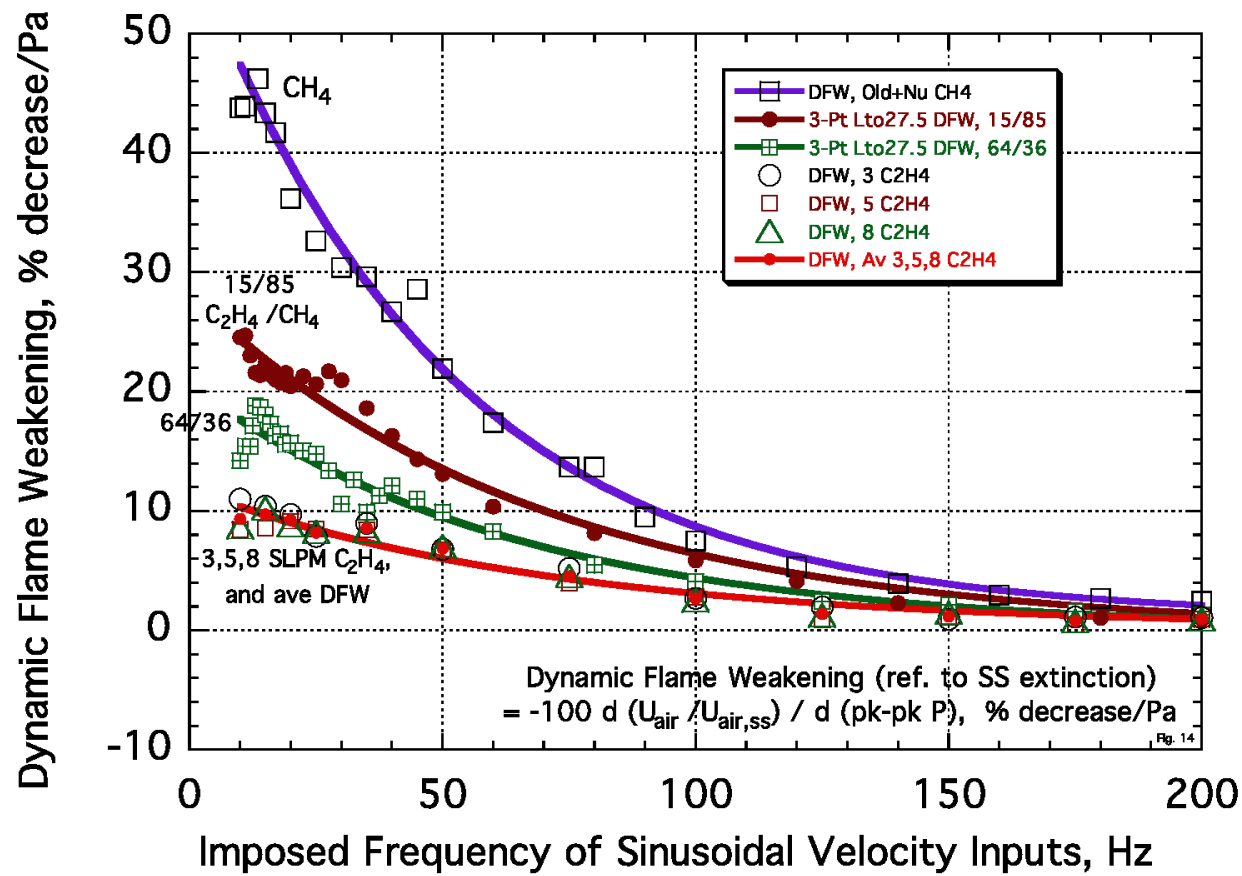

Fig. 14. Exponential decay fit of $\geq 10 \mathrm{~Hz}$ Dynamic Flame Weakening data for extinction of $\mathrm{C}_{2} \mathrm{H}_{4}$, $\mathrm{CH}_{4}$, and $64 / 36$ and $15 / 85 \mathrm{C}_{2} \mathrm{H}_{4} / \mathrm{CH}_{4}$ surrogates vs. Air CFDFs, using $7.2 \mathrm{~mm}$ Pyrex Nozzle OOJB and axially applied sinusoidal velocity (pressure) inputs probed by Microphone (cal @ 5 SLPM).

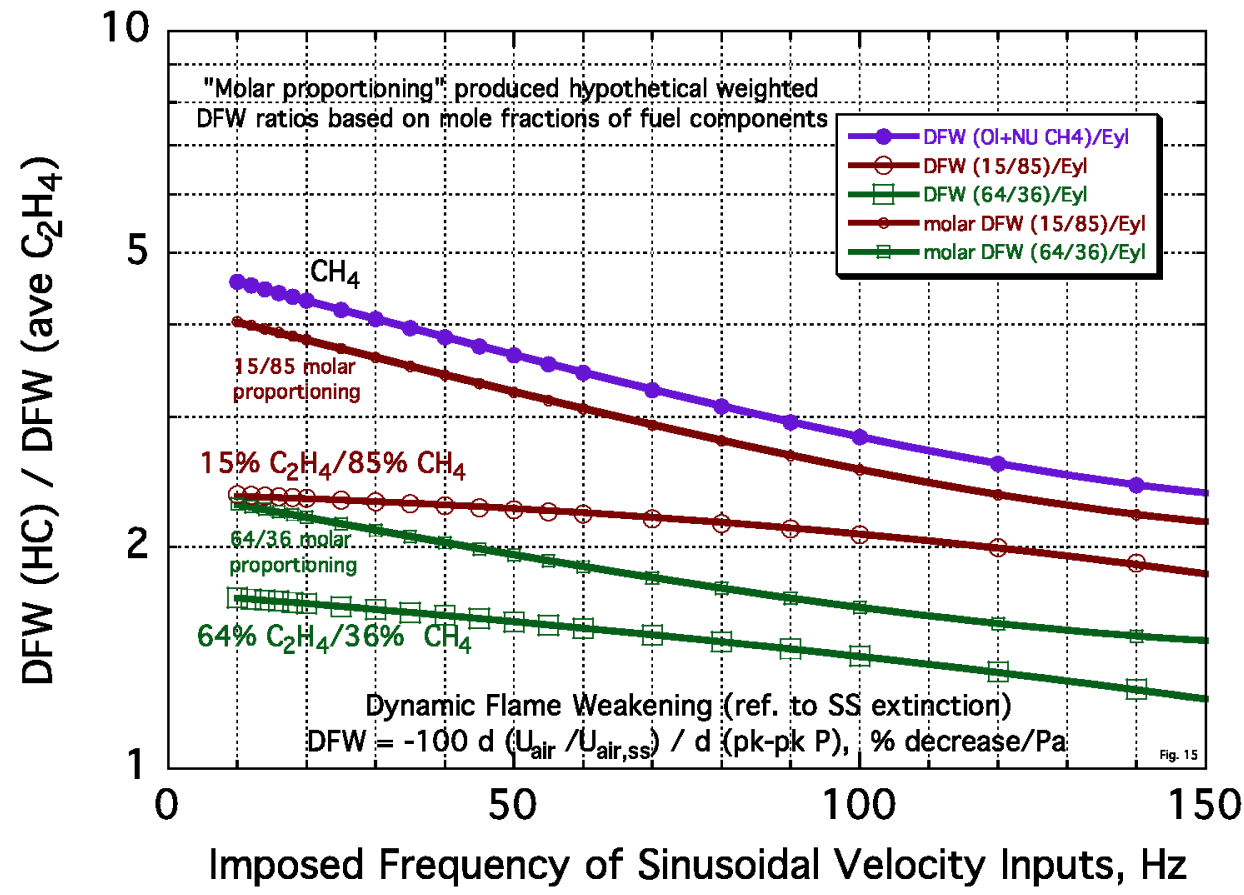

Fig. 15. Empirical Fits of Relative Dynamic Flame Weakening for extinction of $\mathrm{C}_{2} \mathrm{H}_{4} / \mathrm{CH}_{4}$ surrogate Mixtures vs. Air CFDFs, using $7.2 \mathrm{~mm}$ Pyrex Nozzle OOJB and axially applied sinusoidal velocity (pressure) inputs probed by Microphone (cal @ 5 SLPM). Note "molar proportioning" fits of data. 